\title{
The North Atlantic Subpolar Gyre in Four High-Resolution Models
}

\author{
A. M. Treguier, ${ }^{*}$ S. Theetten, ${ }^{*}$ E. P. Chassignet, ${ }^{+}$T. Penduff, ${ }^{\#}$ R. Smith, ${ }^{@}$ L. Talley, $\&$ \\ J. O. BEISMANN, ${ }^{* *}$ AND C. BÖNING ${ }^{+}$ \\ *Laboratoire de Physique des Oceans, CNRS-IFREMER-UBO, Brest, France \\ + RSMAS/MPO, University of Miami, Miami, Florida \\ \#Laboratoire des Ecoulements Geophysiques et Industriels, Joseph Fourier University, Grenoble, France \\ ${ }^{\circledR}$ Los Alamos National Laboratory, Los Alamos, New Mexico \\ \&Scripps Institution of Oceanography, University of California, San Diego, La Jolla, California \\ **NEC High Performance Computing Europe GmbH, Düsseldorf, Germany \\ ++ Institüt für Meereskunde, Kiel, Germany
}

(Manuscript received 10 November 2003, in final form 12 October 2004)

\begin{abstract}
The authors present the first quantitative comparison between new velocity datasets and high-resolution models in the North Atlantic subpolar gyre $\left[1 / 10^{\circ}\right.$ Parallel Ocean Program model (POPNA10), Miami Isopycnic Coordinate Ocean Model (MICOM), $1 \%^{\circ}$ Atlantic model (ATL6), and Family of Linked Atlantic Ocean Model Experiments (FLAME)]. At the surface, the model velocities agree generally well with World Ocean Circulation Experiment (WOCE) drifter data. Two noticeable exceptions are the weakness of the East Greenland coastal current in models and the presence in the surface layers of a strong southwestward East Reykjanes Ridge Current. At depths, the most prominent feature of the circulation is the boundary current following the continental slope. In this narrow flow, it is found that gridded float datasets cannot be used for a quantitative comparison with models. The models have very different patterns of deep convection, and it is suggested that this could be related to the differences in their barotropic transport at Cape Farewell. Models show a large drift in watermass properties with a salinization of the Labrador Sea Water. The authors believe that the main cause is related to horizontal transports of salt because models with different forcing and vertical mixing share the same salinization problem. A remarkable feature of the model solutions is the large westward transport over Reykjanes Ridge [10 Sv $\left(\mathrm{Sv} \equiv 10^{6} \mathrm{~m}^{3} \mathrm{~s}^{-1}\right)$ or more].
\end{abstract}

\section{Introduction}

The subpolar gyre of the North Atlantic is a region of complex dynamics, playing a key role in the variability of climate. Its currents are forced by buoyancy contrasts and overflows from neighboring seas, probably as much as by the wind. Because of the low stratification, topography steers the currents, even in the upper layers. The different water masses, although well defined by the precision of hydrographic measurements, have salinity contrasts small enough that numerical models have difficulty to maintain them. All of those factors make this region especially challenging for ocean modelers.

The purpose of this paper is to document the behavior of state-of-the-art, high-resolution models in the subpolar North Atlantic. Such models have shown good skill in simulating the subtropical gyre. One example is the $1 / 10^{\circ}$ model of Smith et al. (2000), based on the Parallel Ocean Program (POP); another is the $1 / 12^{\circ}$

Corresponding author address: Dr. Anne-Marie Treguier, Laboratoire Physique des Oceans, CNRS-IFREMER-UBO, BP 70, Plouzane, France.

E-mail: treguier@ifremer.fr model of Paiva et al. (1999), based on the Miami Isopycnic Coordinate Ocean Model (MICOM). The French $16^{\circ}$ Atlantic model (ATL6) does not have a fine enough mesh to represent the Gulf Stream system realistically, but it has shown very good results for the deep currents in the subtropical South Atlantic (Treguier et al. 2003). Those three model solutions have never been documented in the subpolar gyre. We also consider the Family of Linked Atlantic Ocean Model Experiments (FLAME) $1 / 12^{\circ}$ model, which has been used by Eden and Böning (2002) to analyze the sources of eddy energy in the Labrador Sea.

The subpolar gyre circulation and its dynamics have been addressed by a number of lower-resolution, eddypermitting models, starting with the $1 / 3^{\circ}$ World Ocean Circulation Experiment (WOCE) Community Modeling Effort (CME). For example, Böning et al. (1996) and Redler and Böning (1997) have considered the effect of the overflows on the circulation by running sensitivity experiments. Myers (2002) and Myers and Deacu (2004) have studied the Labrador Sea circulation and freshwater balance with various representations of the topography. Käse et al. (2001) have tested different forcing mechanisms for the circulation in the Labrador and Irminger Seas, and Biastoch et al. (2003) 
TABLE 1. Characteristics of the four models used in this study. The horizontal grid size is indicated at the equator (the grid is isotropic and refined as the cosine of latitude). For MICOM, the 19 isopycnic layers are characterized by $\sigma_{0}=24.70,25.28,25.77,26.18,26.52$, $26.80,27.03,27.22,27.38,27.52,27.64,27.74,27.82,27.88,27.92,28.00,28.06,28.09$, and 28.12. For vertical mixing, POPNA10 uses the Richardson-dependent formulation of Pacanowski and Philander (1981). MICOM uses a Krauss-Turner (KT) scheme in the mixed layer, and the Richardson-dependent entrainment described in Papadakis et al. (2003) in the interior. ATL6 has a turbulent kinetic energy (TKE) closure, and FLAME has a coefficient dependent on the inverse of the Väisälä frequency $N$. For forcing fields, SST is sea surface temperature and SSS sea surface salinity. B95 refers to the forcing proposed by Barnier et al. (1995), based on a monthly climatology of ECMWF wind and heat flux data for 1986-88.

\begin{tabular}{|c|c|c|c|c|}
\hline Characteristics & POPNA10 & MICOM & ATL6 & FLAME12 \\
\hline Horizontal grid & $1 / 10^{\circ}$ & $1 / 12^{\circ}$ & $1 / 6^{\circ}$ & $1 / 12^{\circ}$ \\
\hline Vertical grid & 42 levels & $19 \sigma_{0}$ layers & 40 levels & 45 levels \\
\hline Domain & North Atlantic & North Atlantic & Atlantic & North Atlantic \\
\hline Horizontal mixing & Biharmonic & Biharmonic & Biharmonic & Harmonic \\
\hline Vertical mixing & Richardson & KT + Richardson & TKE & $1 / N$ \\
\hline Spinup & $5 \mathrm{yr}$ & $6 \mathrm{yr}$ & $8 \mathrm{yr}$ & $15 \mathrm{yr}$ at $1 / 3^{\circ}$ \\
\hline Period & 1985-96 & $1979-86$ & 1979-2000 & $8+8 y r$ \\
\hline Wind forcing & ECMWF daily & ECMWF 6h & ECMWF daily & B95 \\
\hline Heat flux & B95 & ECMWF (bulk) & ECMWF (flux) & B95 \\
\hline SST relaxation & 30 days & Implicit (bulk) & B95 & B95 \\
\hline Evaporation & None & ECMWF (bulk) & ECMWF (flux) & None \\
\hline Precipitation & None & COADS & ECMWF $(\times 0.95)$ & None \\
\hline SSS relaxation & 30 days & 60 days & B95 & 15 days \\
\hline
\end{tabular}

have examined the overflows from the Nordic seas. The comparison of model results with observations has been limited in all these studies.

Regarding the eddy-permitting models, it is interesting to mention the DYNAMO intercomparison of three $1 / 3^{\circ}$ models of the North Atlantic (Willebrand et al. 2001). The models had different vertical coordinates: $z$ (horizontal), $\sigma$ (topography following), and $\rho$ (isopycnic). The subpolar gyre circulation has not been analyzed in detail in those models. One reason was a strong drift in watermass properties, especially in the Labrador Sea. Another reason was the realization that both $z$-coordinate and $\sigma$-coordinate models had too much vertical mixing downstream of the sills forming the boundary between the subpolar gyre and the Nordic Seas (Denmark Straits and the Iceland-Scotland ridge). On the contrary, the version of MICOM that was used in DYNAMO had too little mixing because there was no parameterization of turbulent entrainment between the layers. The $z$-coordinate models we are considering in this study have higher resolution both vertically and horizontally, and the MICOM experiment includes explicit entrainment. Those new model solutions should thus show improvement when compared with the DYNAMO experiments.

Until recently, model-data comparisons in the subpolar gyre have been hindered by the lack of direct velocity measurements. This is a big problem at high latitudes, because the barotropic component of the circulation is large and geostrophic shear brings little information. New measurements are available that allow a quantitative description of currents in the subpolar gyre at finer scales than was previously possible (surface drifters: Reverdin et al. 2003; Flatau et al. 2003; and subsurface floats: Lavender et al. 2000; Bower et al. 2002). This makes possible for the first time a quanti- tative model-data comparison of velocity fields, which is carried out in section 3 of this paper.

Section 4 is devoted to the comparison of barotropic streamfunctions and their link to deep convection patterns. The watermass properties and transports are examined in section 5 and possible explanations for the excessive salinization of the subpolar waters in the models are reviewed.

\section{Models and strategy}

\section{a. Model characteristics}

The model experiments used in this paper have been presented elsewhere and are only briefly described; important parameters are summarized in Table 1. All models have isotropic grids, with the latitudinal spacing decreasing like the longitudinal one according to the Mercator projection. The equatorial resolution is $1 / 12^{\circ}$ for MICOM, $1 / 12^{\circ}$ for FLAME, $1 / 10^{\circ}$ for POP, and $1 / 6^{\circ}$ for ATL6. POPNA10, MICOM, and FLAME are North Atlantic models with closed boundaries, from $20^{\circ} \mathrm{S}$ $\left(28^{\circ} \mathrm{S}\right.$ for MICOM) to $70^{\circ} \mathrm{N}$. ATL6 is an Atlantic model with open boundaries at Drake Passage and south of Africa (Treguier et al. 2001). All four models have a buffer zone in the Nordic seas where temperature and salinity are strongly restored to climatology. Only ATL6 has a mass flux at $70^{\circ} \mathrm{N}\left(1 \mathrm{~Sv}, \mathrm{~Sv} \equiv 10^{6} \mathrm{~m}^{3} \mathrm{~s}^{-1}\right.$, representing the input from the Bering Strait). MICOM and POPNA10 are initialized from the Levitus (1982) climatology, and ATL6 is initialized with the climatology of Reynaud et al. (1998).

The MICOM configuration is based on the parallel version of the code as described in Paiva et al. (1999) and Chassignet and Garraffo (2001). The vertical discretization was chosen to provide maximum resolution 
in the upper subtropical ocean: the vertical density structure is represented by 19 isopycnic layers, topped by an active bulk Kraus-Turner surface mixed layer that exchanges mass and properties with the isopycnic layers underneath. The model is forced by a combination of the European Centre for Medium-Range Weather Forecasts (ECMWF) atmospheric data and COADS precipitations. Heat fluxes and evaporation are calculated using bulk formulas (Paiva and Chassignet 2001). The freshwater flux includes a restoring to climatological surface salinity with a strength that is one-half that of the feedback of SST on the heat flux (resulting in a 60-day relaxation time scale).

The second configuration, ATL6, has been developed as part of the French CLIPPER project. It is based on the $z$-coordinate, rigid-lid version of the primitive equation code OPA8.1 developed at LODYC (Madec et al. 1998). Free-slip boundary conditions are used. The vertical grid has 42 levels with a grid spacing varying from $12 \mathrm{~m}$ at the surface to $200 \mathrm{~m}$ below 1500 $\mathrm{m}$. The ATL6 model has been spun up for 8 years with the ECMWF reanalysis monthly climatology, then integrated for the 15 years of the reanalysis (1979-93), and then with the ECMWF analysis (1994-2000). The heat flux is formulated as suggested in Barnier et al. (1995), using their feedback coefficient for relaxation to the Reynolds SST field but using the interannual ECMWF heat fluxes rather than the climatology of years 1986-88. The typical time scale of the Barnier et al. (1995) heat flux feedback depends on the mixed layer depth; it is about $30-40$ days for $30 \mathrm{~m}$, and smaller for deeper mixed layers. It results from a linearization of bulk formulas and is therefore very close to the bulk formulation of MICOM. The evaporation minus precipitation $(E-P)$ fluxes are formulated as a pseudo salt flux, including river runoff (Treguier et al. 2001); a relaxation of surface salinity to climatology with the same coefficient as the SST is added to the flux.

The third configuration is the North Atlantic model POPNA10 (Smith et al. 2000). It is based on the POP code, derived from the Bryan-Cox $z$-coordinate model and adapted to massively parallel computers (Smith et al. 1992). POPNA10 is a free-surface configuration with 40 vertical levels of spacing ranging from $10 \mathrm{~m}$ at the surface to $250 \mathrm{~m}$ at depth. Vertical diffusion coefficients are calculated using the Richardson-number-dependent formulation of Pacanowski and Philander (1981). The POPNA10 experiment consists in a 5-yr spinup followed by an integration over years 1985 to 1996 . Note that only the winds (ECMWF analysis) have interannual variability; heat fluxes are formulated according to Barnier et al. (1995). The salt flux is simulated by a simple relaxation of surface salinity to Levitus (1982) monthly climatology with a time scale of 30 days in the top model layer.

The fourth model is the $1 / 12^{\circ}$ North Atlantic configuration of the FLAME model hierarchy (Dengg et al. 1999). The model code is based on MOM2.1 (Pac- anowski 1996). There are 45 levels with a spacing of 10 $\mathrm{m}$ in the uppermost level, a smooth increase to $250 \mathrm{~m}$ and constant $250 \mathrm{~m}$ spacing below $2500-\mathrm{m}$ depth. The $1 / 12^{\circ}$ model has been initialized from a 15 -yr spinup of an eddy-permitting, $1 / 3^{\circ}$ FLAME model. The highresolution model has been run with horizontal mixing (FLH experiment), first for three years with high viscosity and then for five years with lower Laplacian viscosity (cf. Eden and Böning 2002, their experiment "nonviscous"). At the beginning of the ninth year, tracer mixing has been switched to isopycnal diffusion (FLI experiment) and a bottom boundary layer parameterization has been activated (Beckmann and Döscher 1997). Results shown here are from the seventh year of the "horizontal" experiment (FLH7). Data from the eighth year of the "isopycnal" run (FLI8) will also be discussed. Throughout the whole integration period the model has been forced by the monthly climatological wind and heat fluxes of Barnier et al. (1995). Sea surface salinity has been restored to climatological values, using a constant time scale of 15 days.

\section{b. Time averages}

Recent studies of the subpolar gyre dynamics focus on its interannual variability in response to atmospheric forcing, which is dominated by the North Atlantic Oscillation (NAO). Three of the models considered here have been forced with interannual variable forcings. We find however that the differences between models are generally larger than the interannual variability within one given model. This is why, as a first step, we focus on the time-mean fields. For POPNA10, the time average that was available to us covers the years 198991, while for MICOM it covers years 1982-86. Both time-averaging periods correspond to a high NAO index. The ATL6 model, which has been run for a longer time period, will be used to sort out the contribution of model differences versus interannual variability in our intercomparison exercise.

\section{Model velocities: Comparison with data}

Figure 1 shows the subpolar region of interest. Bathymetry deeper than $2000 \mathrm{~m}$ is shaded, and the (smoothed) line $f / H=5 \times 10^{-8} \mathrm{~m}^{-1} \mathrm{~s}^{-1}$ is plotted in white. The extent to which the flow departs from $f / H$ contours indicates the importance of wind forcing, dissipation, baroclinicity, and inertial effects. Also indicated on this figure is a path that approximately follows section AR7W across the Labrador Sea, as well as one of the CONVEX sections in the Irminger Sea and Iceland Basin (Bacon 1997).

\section{a. Surface circulation}

A quantitative description of the surface circulation has recently been made possible by the WOCE surface drifters drogued at $15 \mathrm{~m}$ (Reverdin et al. 2003; Flatau et 


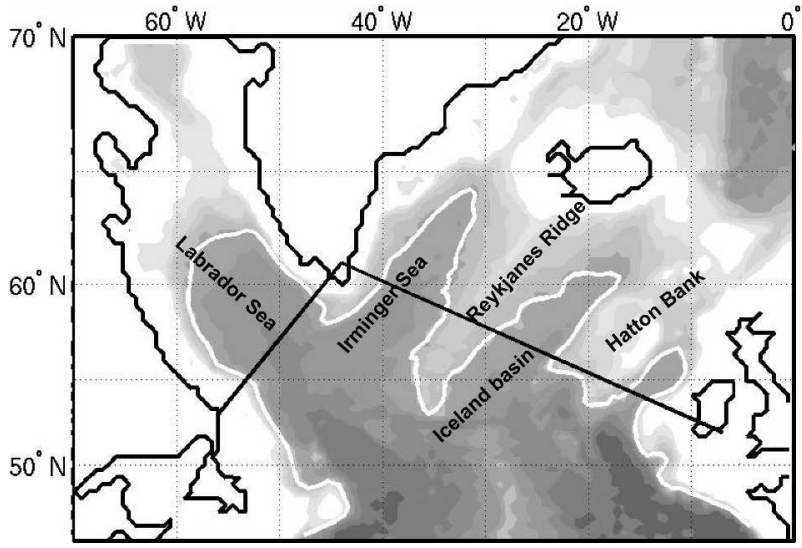

FIG. 1. Map of the subpolar gyre. Topography is indicated in gray. The white line is a smoothed contour of $f / H=5 \times 10^{-8} \mathrm{~m}^{-1}$ $\mathrm{s}^{-1}$. Results are presented along the path of the sections outlined in black.

al. 2003, hereinafter FTN03). We reproduce in Fig. 2a the drifter velocities of FTN03 (average of years 199298) averaged on a $1^{\circ}$ grid. We have averaged the models' time-mean velocities in the same bins. For ATL6, POPNA10, and FLAME (Figs. 2b,c,e), velocities in the second model layer have been chosen $(18,15$, and $15 \mathrm{~m}$, respectively). For MICOM (Fig. 2d), the top-layer velocity is used, which is an average over the depth of the mixed layer $(200 \mathrm{~m}$ in most of the subpolar domain, with maxima of $800 \mathrm{~m}$ in the Irminger Sea and Greenland Current in the annual mean). This velocity is thus generally smaller than in the other models.

Reverdin et al. (2003) and Flatau et al. (2003) pointed out that the subpolar circulation as seen by the drifters is not continuous from east to west (unlike the $f / H$ line of Fig. 1). In the east, two northeast flowing branches are seen: one in the Rockall Trough and one in Maury Channel in the middle of the Iceland Basin (Fig. 2a). To the west, the drifters reveal a strong Irminger Current flowing northward along the western flank of the Reykjanes Ridge, which joins the East Greenland, West Greenland, and Labrador Currents to form a continuous gyre. This gyre is not connected with the eastern part of the basin because the flow on the east flank of Reykjanes Ridge is very weak.

In contrast, the high-resolution models show a welldefined southwestward current along the eastern flank of the Reykjanes Ridge, connecting the Iceland Basin branch to the Irminger Current. In the following, we will refer to this flow as the East Reykjanes Ridge Current. Such a current is to be expected if the water flows along $\mathrm{flH}$ contours and it exists at depth (Lavender et al. 2000; Bower et al. 2002). The drifter sampling is good in the area so that it does not seem a likely source of error. FTN03 find that the (weak) flow observed east of the Reykjanes Ridge is more to the south in negative NAO years, but models show a consistent (and larger than observed) southwestward current every year.
In the eastern basin, both data and models show a strong current branch flowing northward along the continental slope toward the Nordic seas, into the Norwegian Current. Another strong northeastward current branch flows in the Iceland Basin over the deepest topography rather than along the slope (Reverdin et al. 2003; Flatau et al. 2003). This branch is present in all models, although perhaps less well defined in the POP model. It appears linked with another branch (flowing along the slope north of Hatton bank) by permanent meanders and eddies. Reverdin et al. and Flatau et al. suggest that the flow in the Iceland Basin eventually joins the Norwegian Current. However, in the models, it splits in two parts, one that returns southeastward in the East Reykjanes Ridge Current and the other that flows north, mainly by joining the Iceland-Faroe Front. This second path is suggested by some drifters but not emphasized in the time average, according to Reverdin et al. (2003).

The model's picture of the circulation in the Irminger and Labrador Seas is generally in good agreement with the data, and the strength of the boundary current seems quite realistic. Note that MICOM velocities are less comparable to drifters in that area because they are integrated over the mixed layer. Discrepancies are noted in the East Greenland coastal current on the shelf north of $64^{\circ} \mathrm{N}$ : models underestimate it considerably. We will come back to this problem in section 5 .

\section{b. Deep circulation}

We now compare the model outputs with the float data analyzed by Lavender et al. (2000, hereinafter LDO). Gridded velocities at $700 \mathrm{~m}$ have been provided by K. Lavender west of $23^{\circ} \mathrm{W}$ (Fig. 3a). We have further averaged the original data by boxes of four values to avoid cluttering. The velocities are objectively analyzed and very smooth, so that this extra averaging does not change the details of the plot. Other float data have been provided by A. Bower (Bower et al. 2002) in the eastern basin. The binned velocities have been compared with model velocities (not shown).

A very striking feature of the model-data comparison (Fig. 3) is the greater strength of the subpolar gyre in the models. The East Reyjanes Ridge Current is clearly present in both float datasets, but it is much stronger in all the models. The Irminger, Greenland, and Labrador Currents are similarly stronger. We have compared model results with box-averaged float velocities prior to objective analysis provided by K. Lavender, and verified that the model-data difference is not caused by the objective analysis, nor by the fact that data from different float levels were used in the dataset of LDO.

We have tried to investigate the discrepancy further, considering profiles of meridional velocities in the East Greenland Current along $60^{\circ} \mathrm{N}$ (Fig. 4). An estimate of the velocity at $700 \mathrm{~m}$ has been made using the surface velocity from WOCE drifters and the geostrophic shear 
(a)

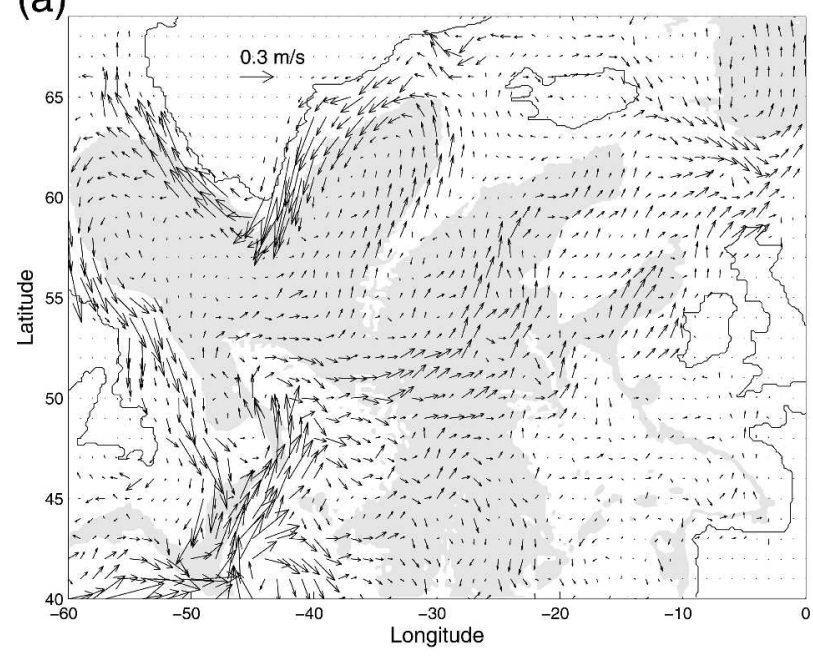

(b)

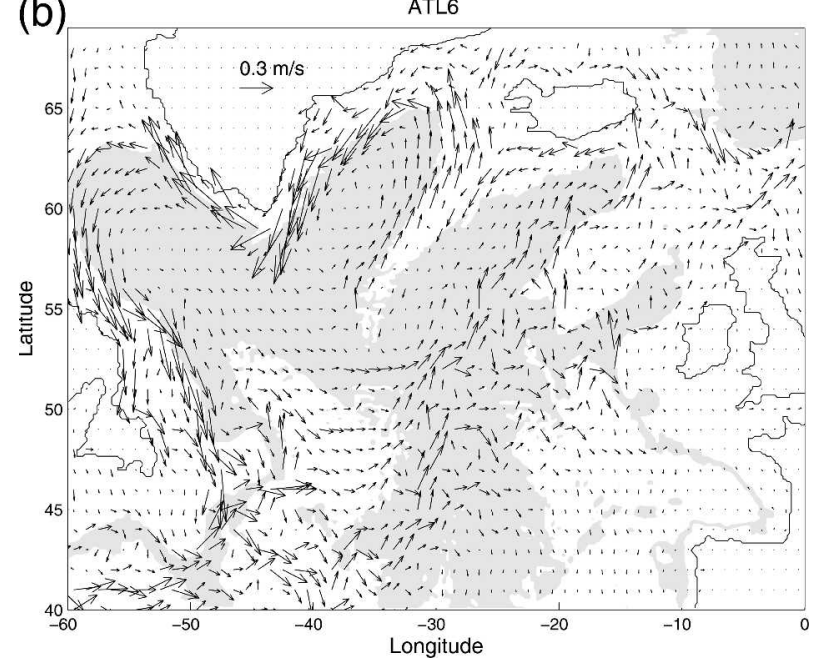

(c)

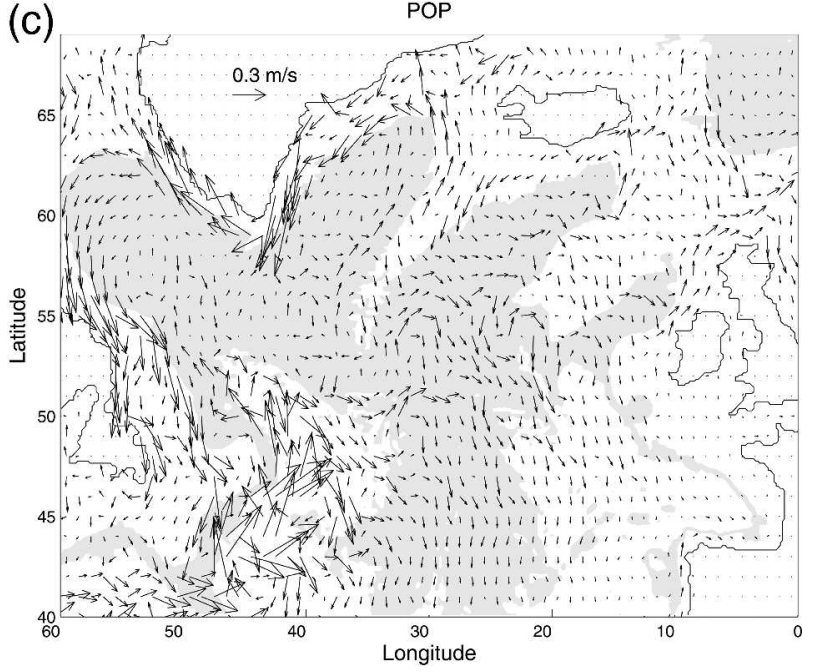

(d)

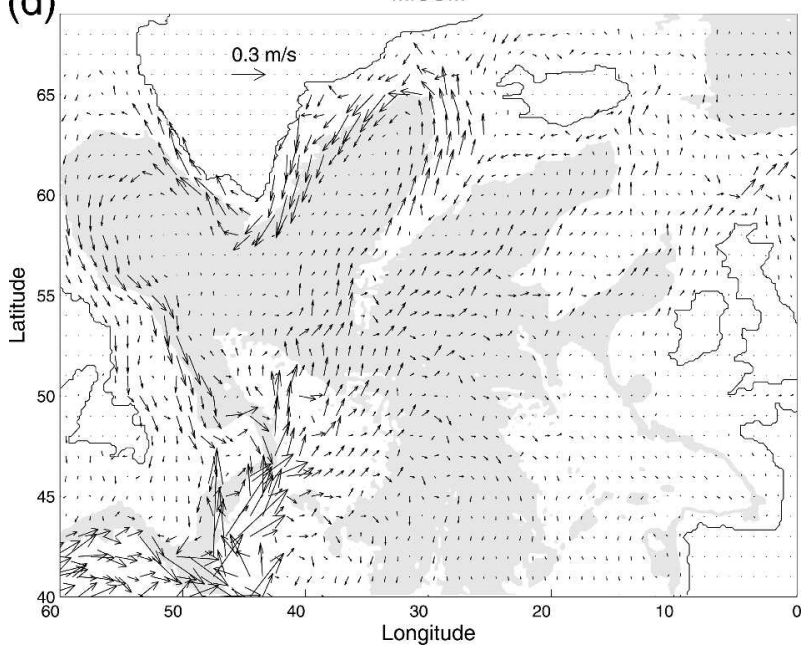

(e)

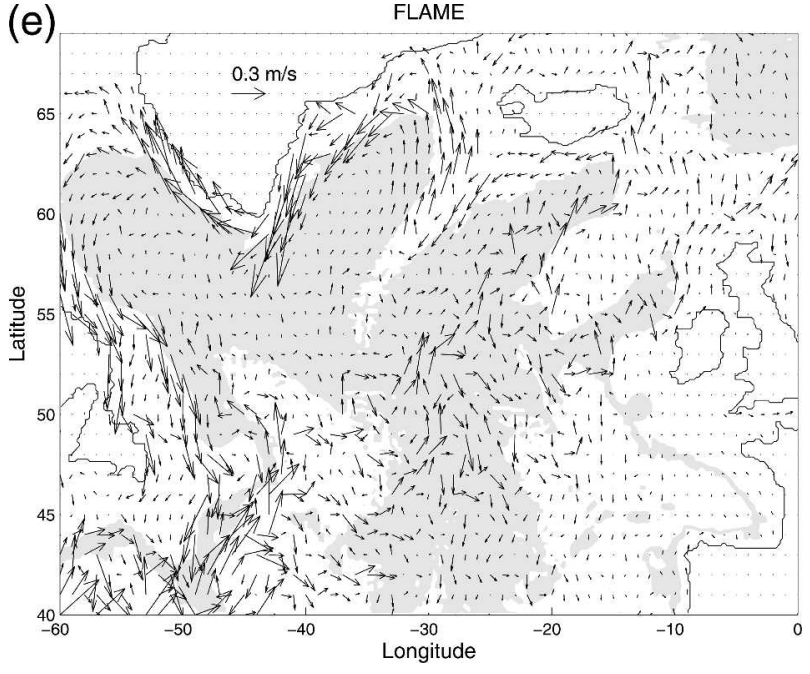

FIG. 2. Time-averaged surface velocities from (a) WOCE drifters (Flatau et al. 2003) and (b)-(e) the ATL6 (1982-86 period), POP (1989-91), MICOM (1982-86), and FLAME FLH7 models, respectively. Topography deeper than $2000 \mathrm{~m}$ is shaded in gray. 
(a)

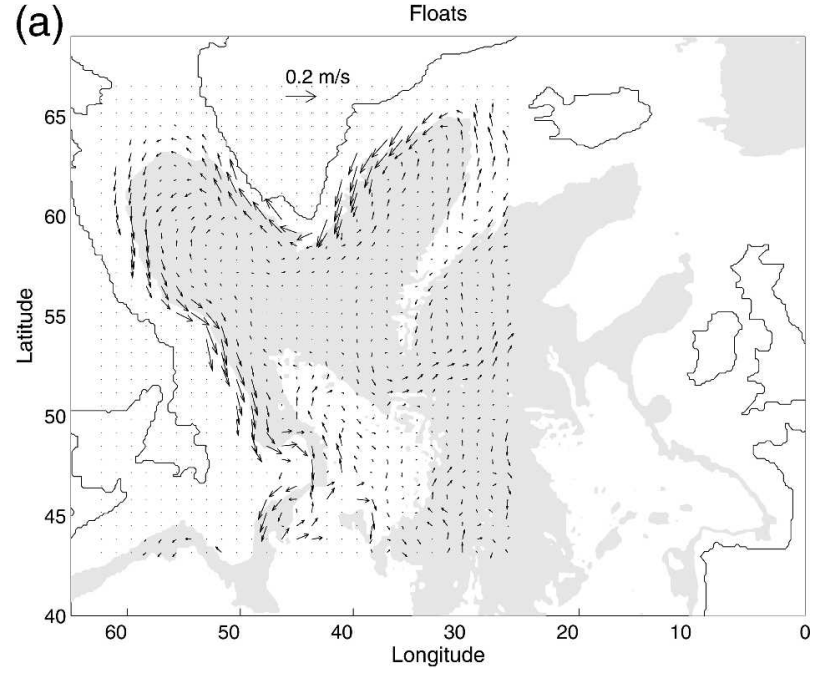

(b)

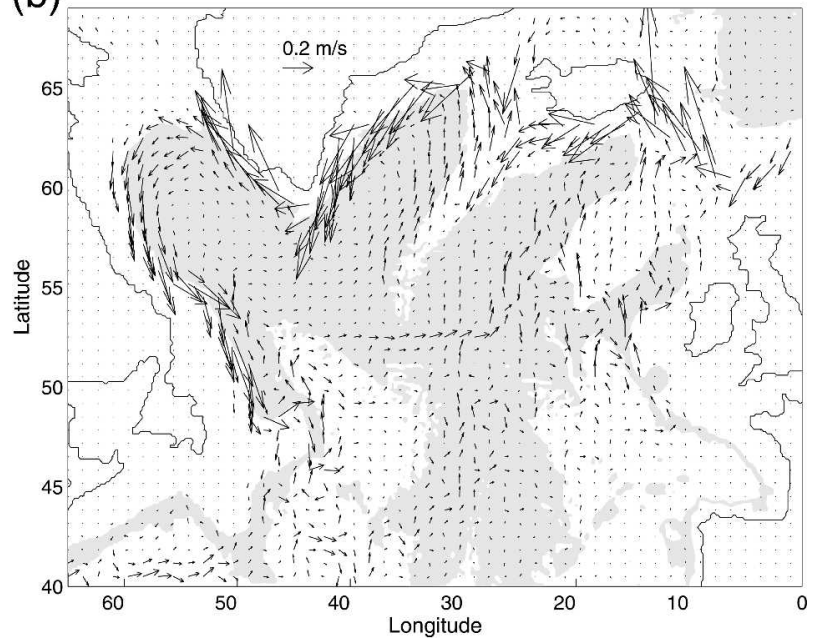

(c)

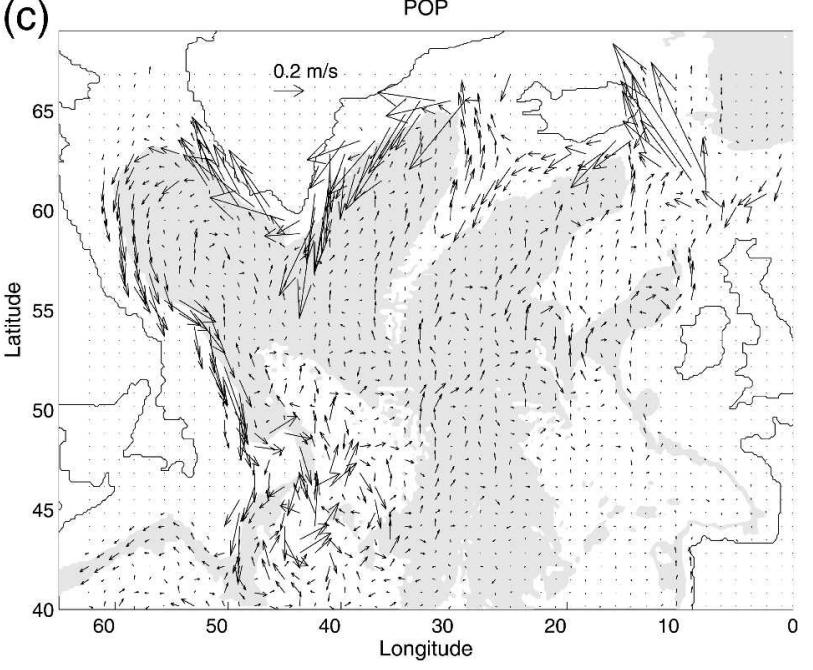

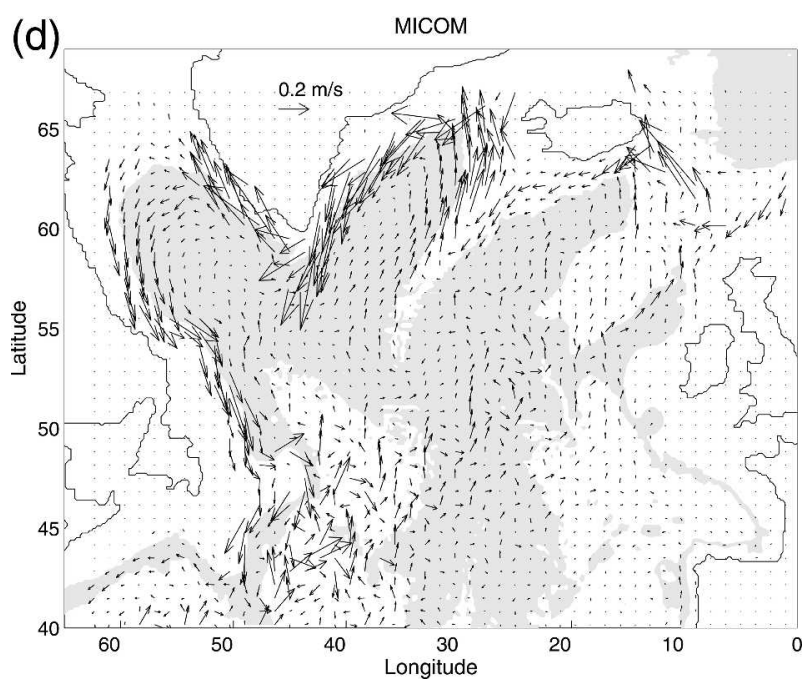

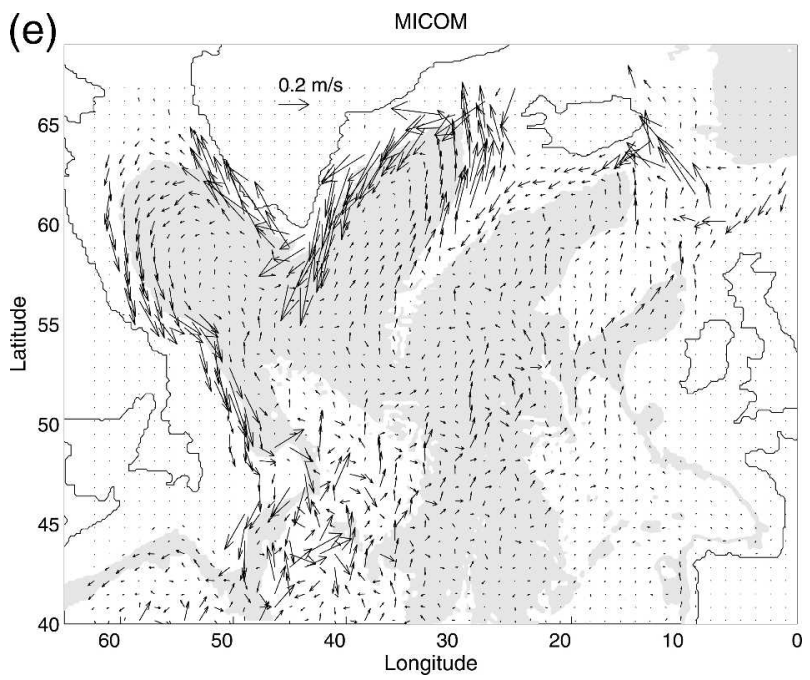

FIG. 3. Time-averaged velocities at depth (a) from float data. Velocities at $700 \mathrm{~m}$ objectively analyzed by Lavender et al. (2000). (b)-(e) Time-averaged velocities from the ATL6, POP, MICOM, and FLAME FLH7 models, respectively. Topography deeper than $2000 \mathrm{~m}$ is shaded in gray. 


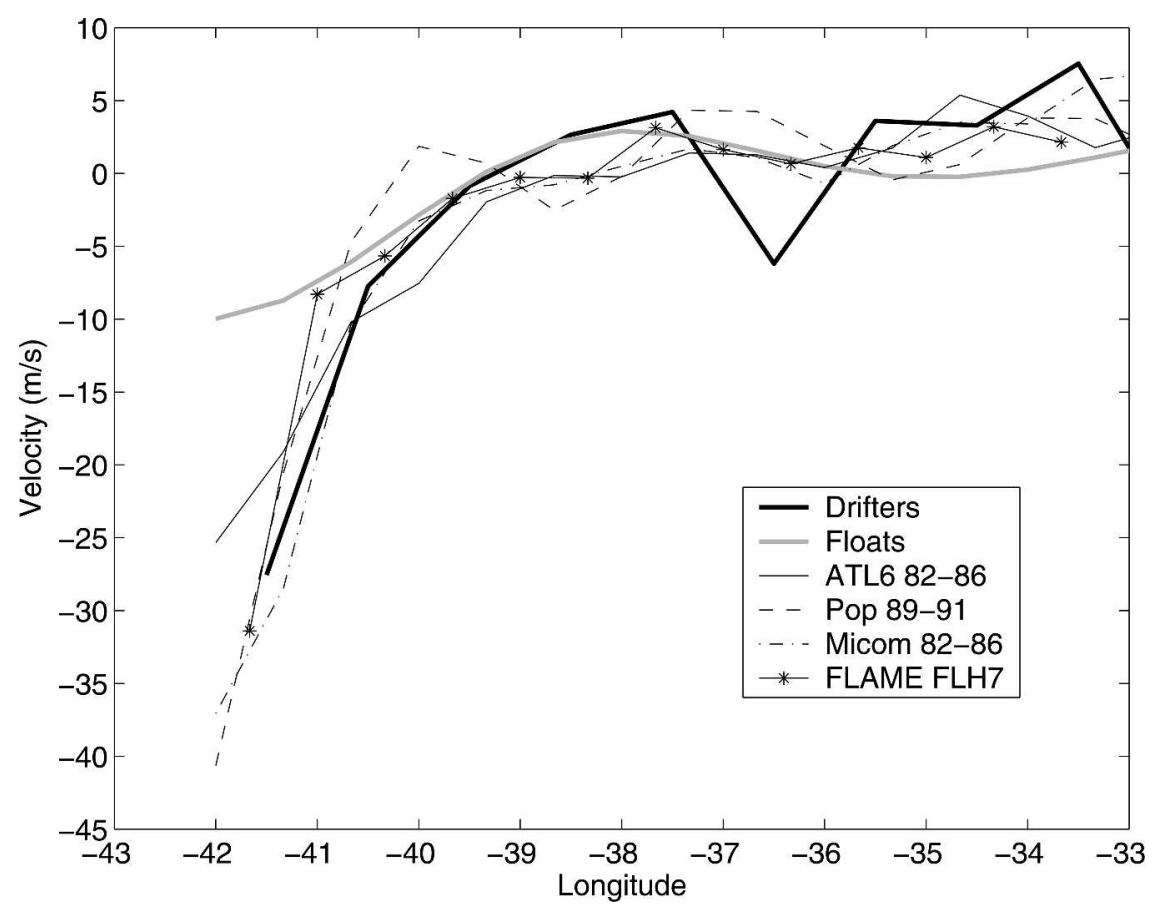

FIG. 4. Velocity profiles at $700 \mathrm{~m}$ along $60^{\circ} \mathrm{N}$. The value for drifters is obtained by correcting the surface drifter velocity using the climatological geostrophic shear. The model values are averaged on the same grid as the float velocities from LDO.

from the climatology of Reynaud et al. (1998). This estimate is in good agreement with the models, while the float velocities are smaller by at least a factor of 2 . Because the velocity on the slope is very barotropic, this means that the total transport implied by the float velocities is small. We have estimated such an absolute transport using the float data at $700 \mathrm{~m}$ as a reference, and the climatological geostrophic shear: the result is 13 $\mathrm{Sv}$ at $60^{\circ} \mathrm{N}$, far below the currently quoted values near Cape Farewell [25 Sv by Bacon (1997) or 33.5 Sv by Clarke (1984)] and also far below the model values (section 4).

We conclude that the gridded float data cannot be used to infer a boundary current transport or to assess the boundary current strength in models. One problem may arise from the fact that float velocities are an integral between two surfacings of each float, over a period from 3.5 to 20 days for the dataset of LDO. Looking at float displacements reveals that a few velocity values near $60^{\circ} \mathrm{N}, 45^{\circ} \mathrm{W}$ come from floats that traveled around the tip of Greenland. Deriving an average velocity between two positions on each side of Greenland without taking into account the actual path around the cape underestimates the true speed. If the floats are assumed to have followed a bathymetry contour, the velocity estimate is closer to the models velocity maxima but is very dependent on the bathymetric product used (K. Lavender 2003, personal communication). Another possible source for the discrepancy between model and float velocities in the boundary current is inadequate sampling by the floats (which may not remain in the narrow region of large velocities). A more detailed float-model comparison would certainly require actual simulation of float trajectories in the models

Although a quantitative comparison is not possible, Fig. 3 shows interesting qualitative features. In the Labrador Sea, LDO noted the presence of a recirculation branch offshore of the Labrador Current. This feature is well reproduced in POPNA10, in FLAME, and exists to some extent in MICOM, but not in ATL6: it will be discussed in more detail in section 4. In the Iceland Basin, the separation of the northward flowing current into two branches, which appeared in the surface velocities, is clear at depth in models (in agreement with the float data of Bower et al. 2002). Considering what we have called the East Reykjanes Ridge Current, float data show that, upon reaching the southern tip of the ridge, part of the water veers toward the east and recirculates in the Iceland Basin (Fig. 3a, see also Fig. 2a of Lavender et al. 2000). All models rather emphasize a continuous flow all around the Reykjanes Ridge. Here, as well as in the surface layers, the model currents seem to follow the $\mathrm{f} / \mathrm{H}$ contours much more than the observed ones. If, as suggested by the floats, the current separates from the topography at that location, dynamics are certainly complex, and involve inertia and instabilities, that may not be represented even at $1 / 12^{\circ}$ resolution. Perhaps also the Faroe Bank channel overflow and its interaction with the Iceland basin circulation are misrepresented. New data have recently been gathered 


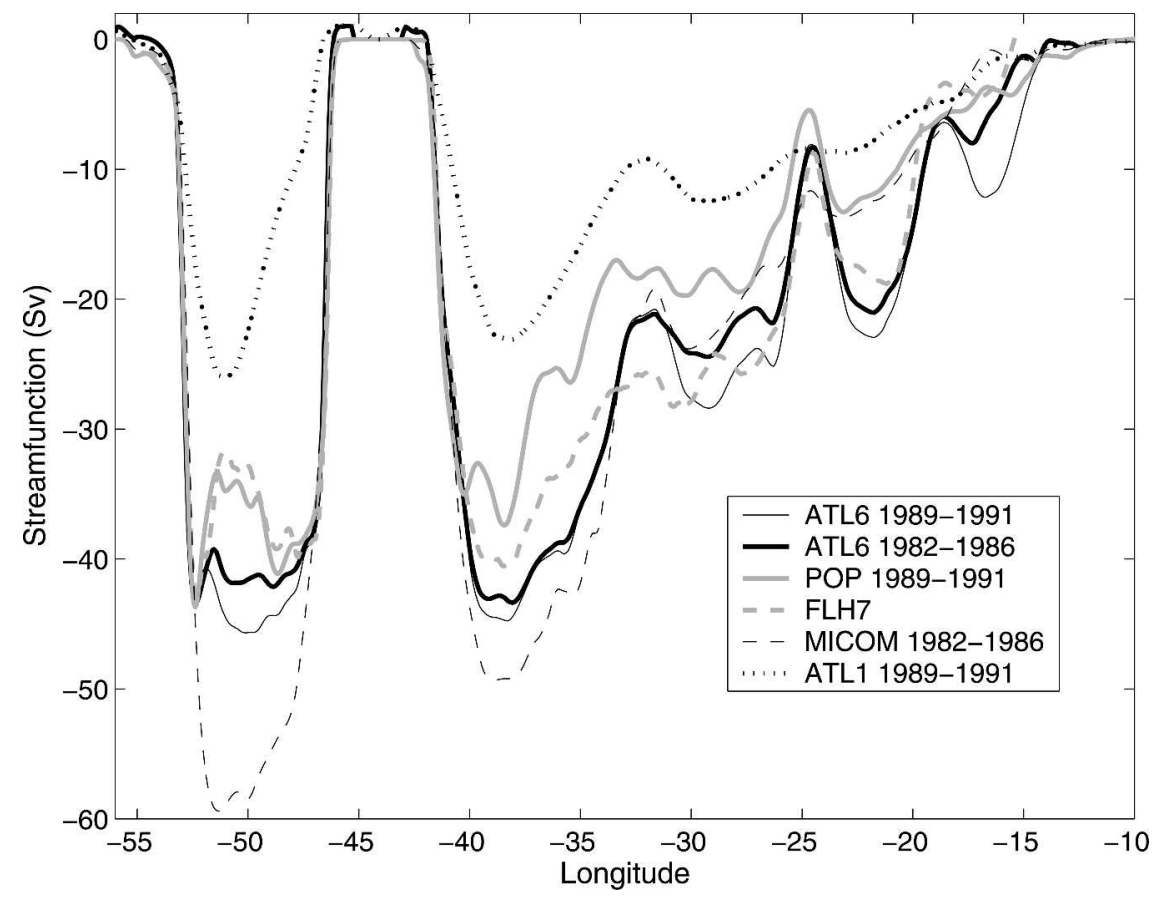

FIG. 5. Barotropic streamfunctions (Sv) along the sections indicated in Fig. 1. For the ATL6 model, two different time averages are shown. Other models are the $1^{\circ}$ model ATL1, POP, MICOM, and FLAME FLH7.

in that area, and further model-data comparisons will be needed.

In the North Atlantic Current (NAC), Bower et al. (2002) find that floats cross the midAtlantic ridge at three locations corresponding to the Charlie-Gibbs Fracture Zone $\left(\mathrm{CGFZ}, 53^{\circ} \mathrm{N}\right)$, the Faraday Fracture Zone $\left(\mathrm{FFZ}, 50^{\circ} \mathrm{N}\right)$ and the Maxwell Fracture Zone $\left(\mathrm{MFZ}, 48^{\circ} \mathrm{N}\right)$. Those three branches seem especially well represented in FLAME. In other models, one branch is often stronger than the others. In ATL6, the CGFZ branch is very strong and surprisingly zonal. In POP, the FFZ branch dominates, and the flow crossing the Mid-Atlantic Ridge has a stronger meridional component. This meridional character is even more accentuated in MICOM. The precise structure of the North Atlantic Current is not robust across models, perhaps due to different representations of the bathymetry at different model resolutions. Modelers sometimes suggest that there may be a link between the representation of the Gulf Stream separation and the downstream path of the NAC: such a link is not obvious in the models presented here.

\section{Strength of the subpolar gyre}

\section{a. Barotropic streamfunction}

A section of barotropic streamfunction along the sections outlined in Fig. 1 is represented in Fig. 5. Variations are large between the models, even though all of them are forced by ECMWF winds. This is in agreement with the view that the subpolar gyre does not obey simple Sverdrup dynamics [a fact already noted in a $1 / 3^{\circ}$ model by Bryan et al. (1995)]. The importance of viscosity, topography and other numerical factors is emphasized by a comparison between the low resolution model ATL1 (dotted line in Fig. 5) and its $1 / 6^{\circ}$ counterpart. In ATL1 the barotropic transport is cut by half. A similar difference exists between the highresolution MICOM case and the $1^{\circ}$ version of that model (not shown).

Interannual variability is not negligible, as seen from the two continuous black curves for two averaging periods of ATL6. In that particular model, the annual average of transport at Cape Farewell $\left(42^{\circ} \mathrm{W}\right)$ varies from a minimum of $38 \mathrm{~Sv}$ (in 1980) to a maximum of 53 $\mathrm{Sv}$ (in 1995) followed by a decline to $42 \mathrm{~Sv}$ (in 2000). A short-term variability is superimposed on those trends (not shown). Part of this signal may be due to model drift, but we note that the weakening of the gyre between 1995 and 2000 is observed by altimetry (Häkkinen and Rhines 2004). Near Cape Farewell, the ATL6 decreases in sea surface height $(10 \mathrm{~cm}$ between 1995 and 2000) and in transport (11 Sv) compare well with the Häkkinen and Rhines estimates. We assume that ATL6 reproduces the right order of magnitude of the interannual variability, and in that case the differences between years 1989-1991 and years 1982-1986 appear too small to explain the large differences between the different models. 
Going from west to east in Fig. 5, we first note that all high-resolution models have a large transport in the Labrador Current system. Except for MICOM, all highresolution models reach a relative maximum of about $43 \mathrm{~Sv}$ near the western end of the section, close to the value of $44 \mathrm{~Sv}$ estimated by Pickart et al. (2002). Those authors found that almost $10 \mathrm{~Sv}$ of this flow recirculates northward. As appeared from the velocity vectors in Fig. 3, the recirculation in the Labrador Sea is well marked in POP and FLAME, with an amplitude reaching $10 \mathrm{~Sv}$, as in Pickart et al. (2002), but larger than suggested by Lavender et al. (2000). In a recent paper, Spall and Pickart (2003) argue that the recirculations in the Labrador Sea could result from remote forcing by the extremely intense wind stress curl found in winter west of Greenland (in the Irminger Sea). All four models are forced by a wind stress curl including this signal (especially strong in ECMWF winds), but only two models have a significant recirculation. Spall and Pickard's theory implies that the recirculation should have a seasonal cycle. Over the three years 1989-91, there is a hint of seasonal signal in POPNA10, but three years are not enough to quantify it because of the superposition of high-frequency, seasonal, and interannual variability. Although this recirculation may be wind-forced, the large difference we find here between models implies that high-order dynamics must be involved in setting the recirculation amplitude. Käse et al. (2001) find it to be extremely sensitive to the representation of topography, with a recirculation reaching $20 \mathrm{~Sv}$ in an idealized model with $1 / 6^{\circ}$ resolution and partial step topography. Such a sensitivity is also found by Myers and Deacu (2004).

Let us now consider the Irminger Basin (longitudes from $45^{\circ}$ to $32^{\circ} \mathrm{W}$ in Fig. 5). All high-resolution models show a thin and intense East Greenland Current (30-48 $\mathrm{Sv})$. This is larger than most estimates from observations. Bacon (1997), for instance, calculates $26.5 \mathrm{~Sv}$ through the CONVEX section. A large transport, though, is in agreement with estimates farther downstream at Cape Farewell (30-50 Sv; Clarke 1984; Reynaud et al. 1995). The inflow of water by the Irminger Current is distributed quite differently according to the model considered. ATL6 and MICOM have a very thin Irminger Current flowing next to the slope of the Reykjanes Ridge, while POP and FLH7 have a more distributed inflow (POP showing distinct jets).

The section crosses the Reykjanes Ridge near its tip at a location where the east Reykjanes Ridge Current is weak: its signature can be seen in all models between $32^{\circ}$ and $30^{\circ} \mathrm{W}$ with amplitudes from 2 to $7 \mathrm{~Sv}$. The current branch flowing in the middle of the Iceland Basin $\left(25^{\circ} \mathrm{W}\right)$ is strong in all models, with a total transport of $10-15 \mathrm{~Sv}$; however, models show a recirculation to the south on the northern flank of Hatton Bank $\left(57^{\circ} \mathrm{N}, 25^{\circ}-23^{\circ} \mathrm{W}\right)$, with similar amplitude. The map of velocities at $700 \mathrm{~m}$ (Fig. 3) hints to the presence of complex recirculations near the tip of Hatton Bank, which may be present in the float dataset but are filtered out by the objective analysis in the maps of Bower et al. (2002). It is encouraging to find that models agree on the patterns of such recirculations, although the amplitudes differ. This suggest that high-resolution models can provide a useful tool to help interpret data in those regions.

\section{b. Deep convection}

A direct relationship between deep convection and the horizontal circulation of the subpolar gyre has been recently demonstrated in a model by Eden and Willebrand (2001). Could differences in convection patterns explain the different circulations in our highresolution models? Examples of mixed layer depths at the end of March for POPNA10, MICOM, and ATL6 are shown in Fig. 6, interpolated onto the same section as in Fig. 5. In the $z$-coordinate models the mixed layer depth has been calculated using the potential density, and looking for the depth at which $\sigma_{0}$ exceeds its surface value by $0.01 \mathrm{~kg} \mathrm{~m}^{-3}$. For MICOM it is the depth of the top model layer. Interannual differences are large (cf. the two ATL6 lines for different years) but the differences between models clearly stand out. We have verified that the instantaneous values chosen for Fig. 6 are representative in that respect. POPNA10 does not seem to suffer from excessive convection (the maximum depth in the Labrador Sea is $1750 \mathrm{~m}$ ). On the contrary, in both ATL6 and MICOM, convection reaches the bottom in the Labrador Sea and in the Irminger Sea. Regarding the FLAME experiments (not illustrated), their maximum convection depth in the Labrador Sea seems realistic, for instance when compared with the recent observations of Lavender et al. (2002). In the Irminger Sea, experiment FLH7 with horizontal mixing has a pattern similar to ATL6, while FLI8 is closer to POPNA10.

Convection patterns are perhaps the most sensitive feature of ocean models, and the present highresolution models are no exception. Differences among models could be due to different forcings: ATL6 and MICOM use interannual fluxes from the ECMWF reanalysis, while POPNA10 and FLAME have climatological heat flux from Barnier et al. (1995), derived from years 1986-88 (years of weak cooling). Moreover, POPNA10 and FLAME represent the freshwater flux by a simple relaxation to sea surface salinity while the other models add an explicit evaporation and precipitation term. Another possible cause of differences is model resolution and eddy activity: eddies are believed to play a key role in the restratification of the Labrador Sea after each winter convection event (Chanut 2003), a process that is underestimated in the ATL6 model because of the lower spatial resolution as shown by a comparison of model and satellite EKE (not reproduced here). Regarding MICOM, note that the vertical resolution is poor in weakly stratified regions: only four layers have a significant thickness in the Labrador Sea. 


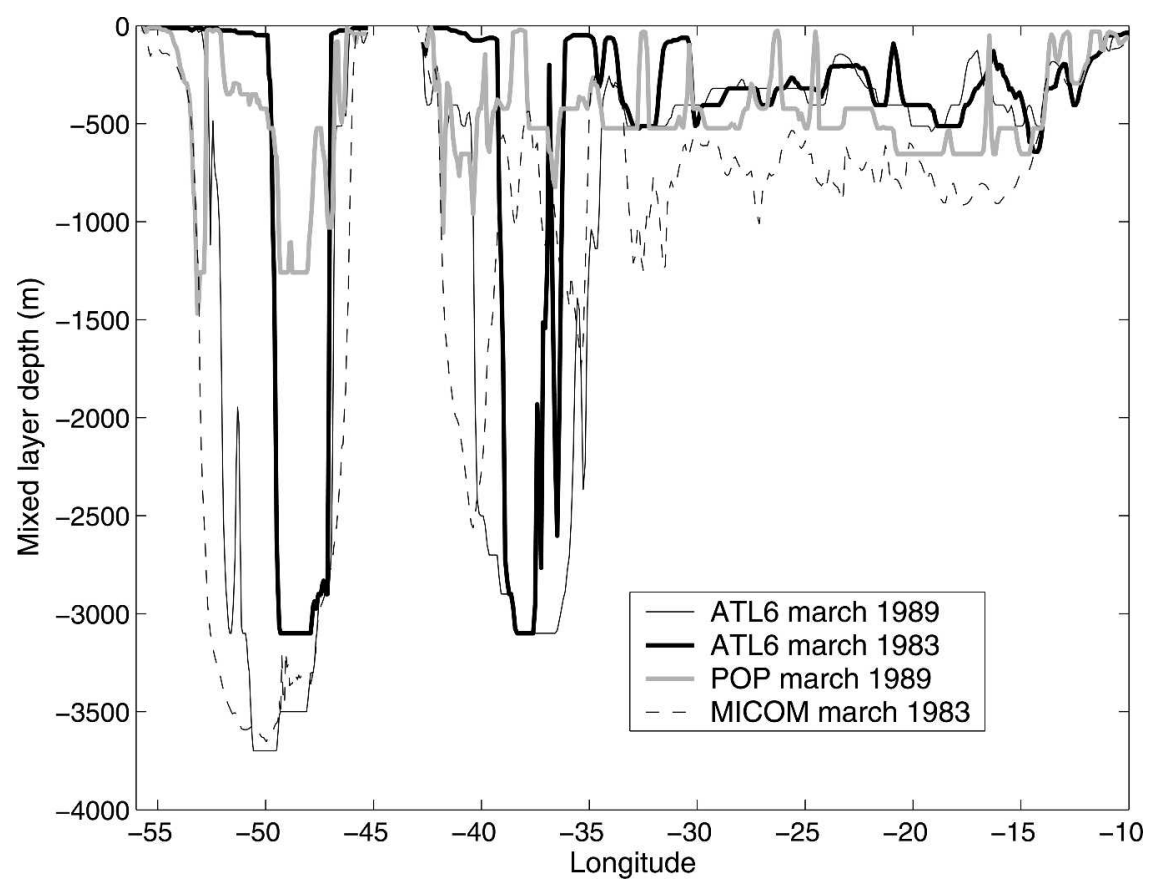

FIG. 6. Instantaneous mixed layer depths at the end of March interpolated onto the section represented in Fig. 1.

To look for a relationship between barotropic transport and convection, let us consider a 20 -yr-long time series from the ATL6 model. Figure 7 shows barotropic transport, mixed layer depth and vertically averaged density for the Labrador Sea and Irminger Sea. Each curve is a deviation from the initial value, normalized by its standard deviation. Streamfunction, densities, and mixed layer depth are averaged over the square boxes mapped in Fig. 8. Those series can be compared with Fig. 5 of Eden and Willebrand (2001, hereinafter EW01). EW01 used a coarse-resolution model forced by interannual atmospheric variability [based on 50 years of National Centers for Environmental Prediction (NCEP) reanalysis]. They found that an increase of convection in the Labrador Sea was followed, 2-3 years later, by an increase in the subpolar gyre transport by 2 Sv. They attributed this effect to the coupling of baroclinicity and topography (the so-called JEBAR effect).

For the ATL6 model in the Labrador Sea (Fig. 7a), the barotropic transport peaks in 1985 and 1994/95, as in EW01, and the peak amplitude is of order one standard deviation $(4.5 \mathrm{~Sv})$, two times larger than in EW01's low-resolution model. Figure 7a suggests a correlation between the streamfunction and the mixed layer depth, although it is less well defined here than in EW01. This may be due to the fact that convection sometimes reaches the bottom and remains constant in ATL6, for instance between 1988 and 1995. The same happens in the Irminger Sea (Fig. 7b). On the other hand, the barotropic streamfunction seems also corre- lated with the average density (dashed line in Fig. 7), even more so than with the mixed layer depth. The barotropic transport is thus linked with thermodynamics in ATL6, as in EW01's model: perhaps this is also a feature of other models.

The maximum strength of the barotropic transport between some models varies in the same way as the deep convection in the Labrador Sea: POPNA10 has the lowest, ATL6 is intermediate, and MICOM has the strongest. On the other hand, the FLAME experiments FLH7 and FLI8 do not follow that pattern, with relatively small changes in streamfunction strength but large differences in convection depths between the two experiments with different parameterizations. Numerical factors (representation of topography, dissipation) play a part, as demonstrated by the difference between ATL1 and ATL6 in Fig. 5. ATL1 and ATL6 have similar convection patterns and very different transports. Sensitivity to the bottom boundary layer parameterization and to the use of the Gent and McWilliams eddy parameterization has also been found in the FLAME $1 / 3^{\circ}$ models (J. Dengg 2003, personal communication). We conclude that differences in deep convection patterns are a likely source of differences in barotropic transport, but not the only one. This issue is certainly easier to investigate by considering a suite of sensitivity studies with one single model rather than in the framework of a model intercomparison. From that point of view, the robustness of the dynamical relationship found by EW01 (and confirmed in ATL6) is encouraging; one hopes that results from sensitivity studies car- 

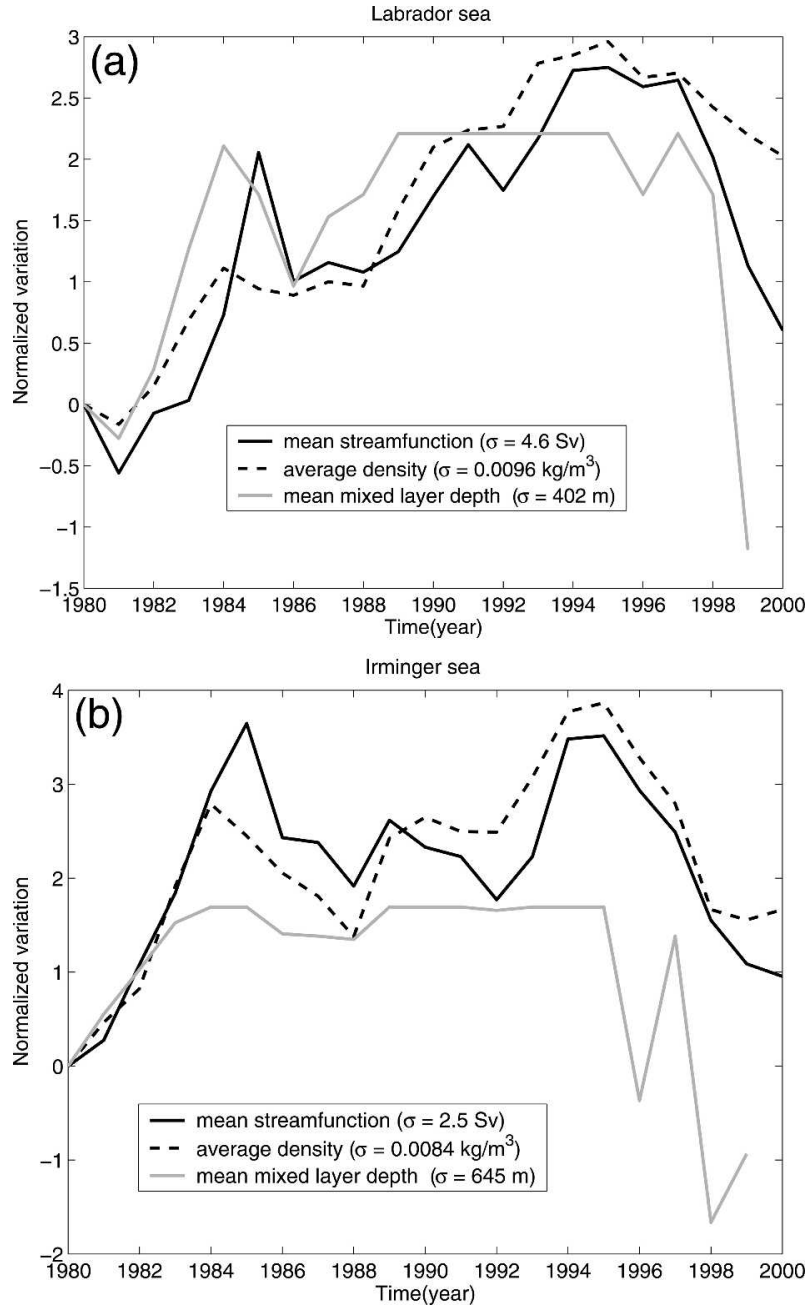

FIG. 7. Evolution of barotropic streamfunction, density, and mixed layer depth averaged over the (a) Labrador Sea box and the (b) Irminger Sea box outlined in Fig. 8, for the ATL6 model. Changes from the initial value (year 1980) are normalized by the standard deviation $\sigma$ of the series (indicated in the legend).

ried out with one single model will be applicable to other models as well.

\section{Salinization of water masses}

\section{a. Temperature and salinity profiles}

The models have been initialized by climatology, but the temperatures and salinities after a few years of experiment have drifted significantly. Figure 8 compares the salinity at $700 \mathrm{~m}$ for the climatology and the POP model. The water in the Labrador and Irminger Seas has become saltier (almost all water with salinity lower than 34.95 psu has disappeared). A tongue of water with salinity higher than 35 psu is found all around Greenland and the Labrador Sea. A similar salinization is found in CLIPPER, in FLAME, and even stronger (a)

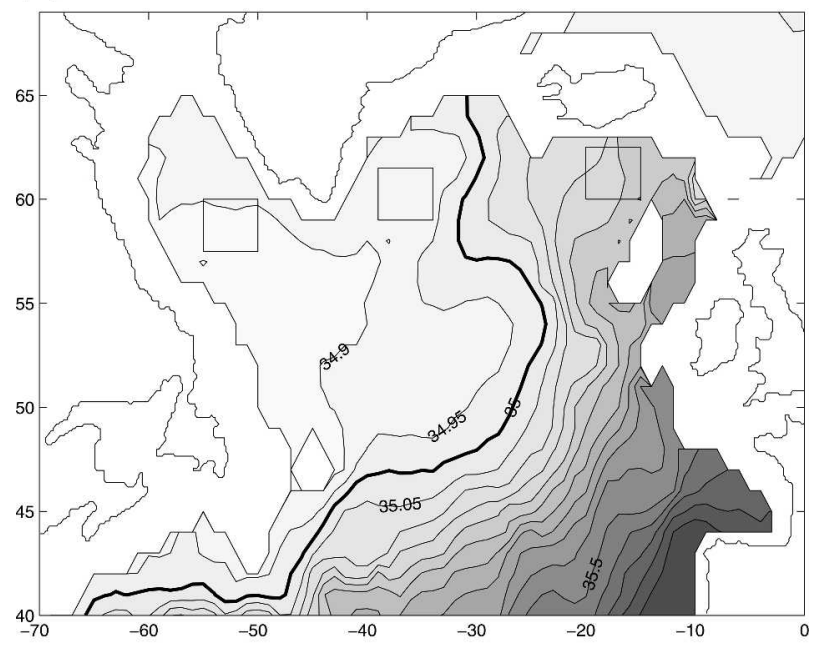

(b)

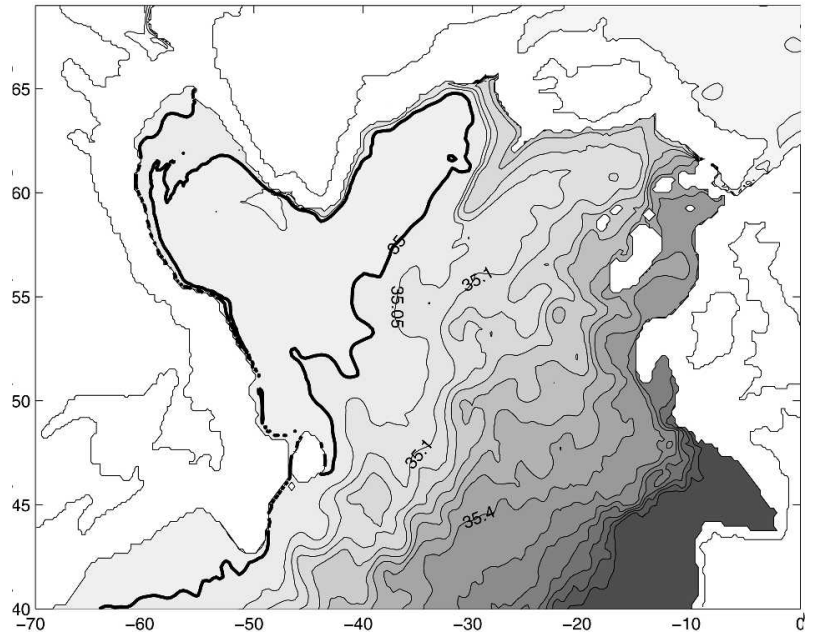

FIG. 8. (a) Salinity at $700 \mathrm{~m}$ from the climatology of Reynaud et al. (1998). Contour interval is 0.05 psu (the 35-psu contour is thicker). The three boxes represent the regions in which profiles will be extracted. (b) Salinity averaged over years 1989-91 at level $21(730 \mathrm{~m})$ for the POP model. Same contour intervals.

in MICOM. This problem was also found in the DYNAMO models.

For intercomparison we have calculated vertical profiles in the three boxes indicated in Fig. 8, for both the climatology and three of the models. The FLAME model results (not shown) are generally close to POPNA10, although with a higher salinity in the Irminger Sea and Iceland Basin. Let us consider first the Labrador Sea (Fig. 9). The water column has become completely homogeneous in ATL6 and MICOM because of excessive convection. In POPNA10, temperature profiles indicate that the deepest dense waters have been lost (below $2600 \mathrm{~m}$ ) but the intermediate stratification is preserved. Despite its better temperature profile, POPNA10 overestimates the salinity as the 

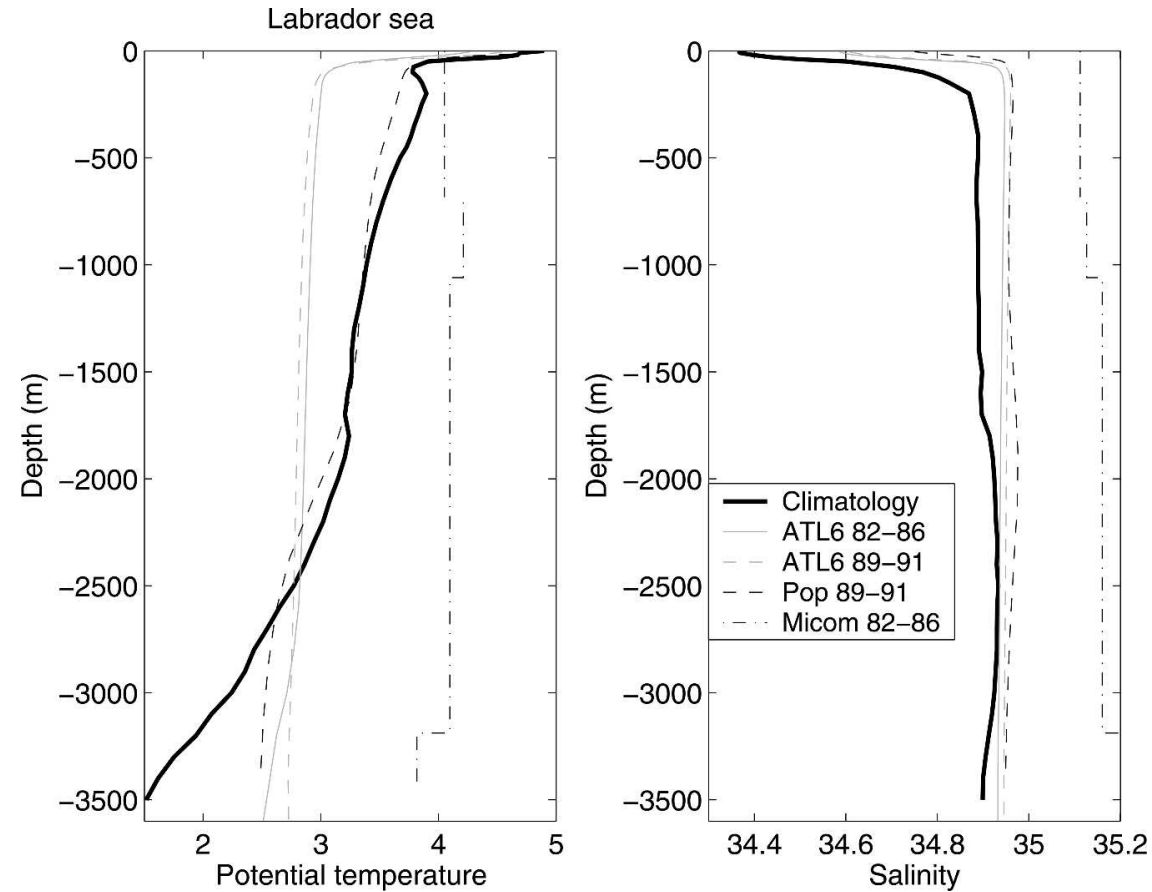

FIG. 9. (left) Temperature and salinity profiles averaged over the Labrador Sea box outlined on Fig. 8. The curves correspond to the climatology of Reynaud et al. (1998), and the different models.

other models do. This suggests that the salinization is not directly linked with surface forcing and convection.

In the Irminger Sea (Fig. 10), the behavior is similar: excessive convection in ATL6 and MICOM only, but salinization in all models. In the Iceland Basin (Fig. 11), there is no deep convection and temperature profiles from the models are closer to the climatology. The salinity is too high in MICOM, but in ATL6 and
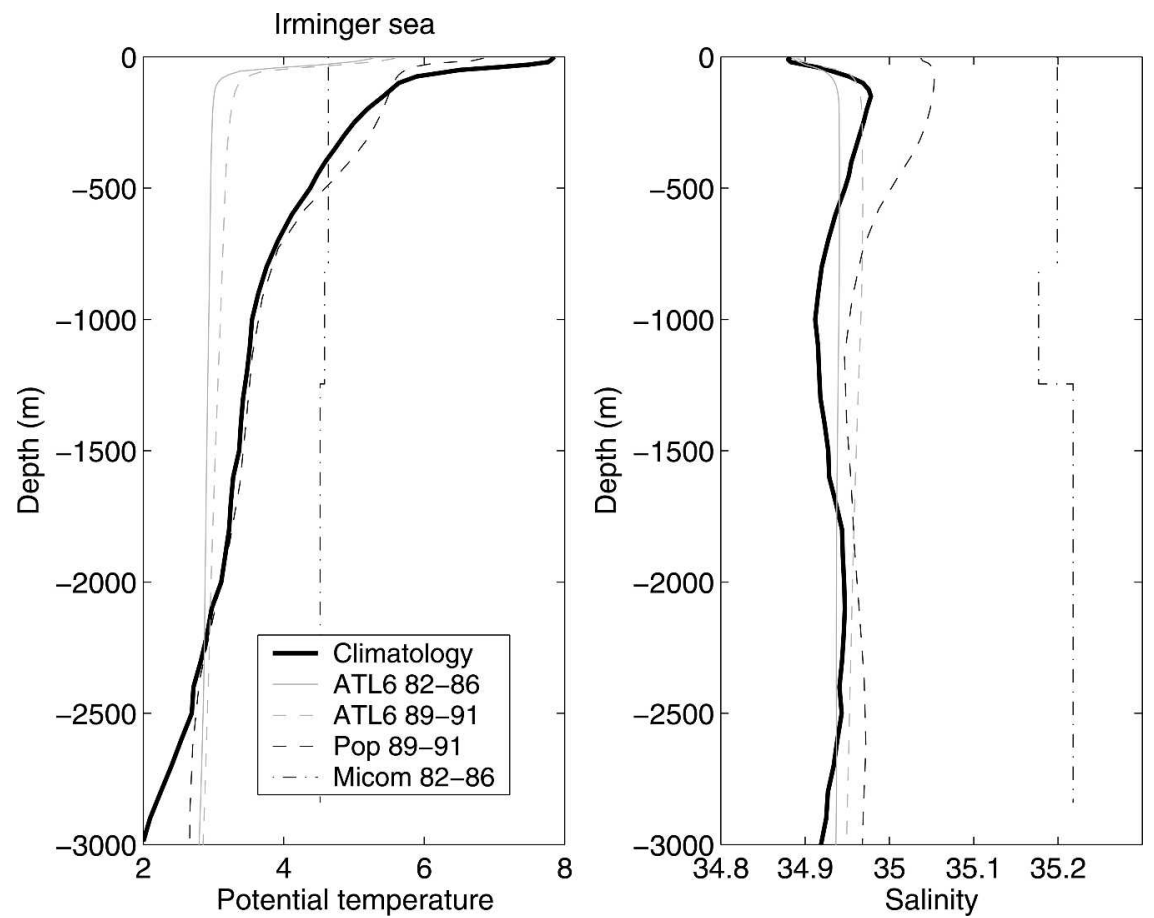

FIG. 10. As in Fig. 9 but for the Irminger Sea. 

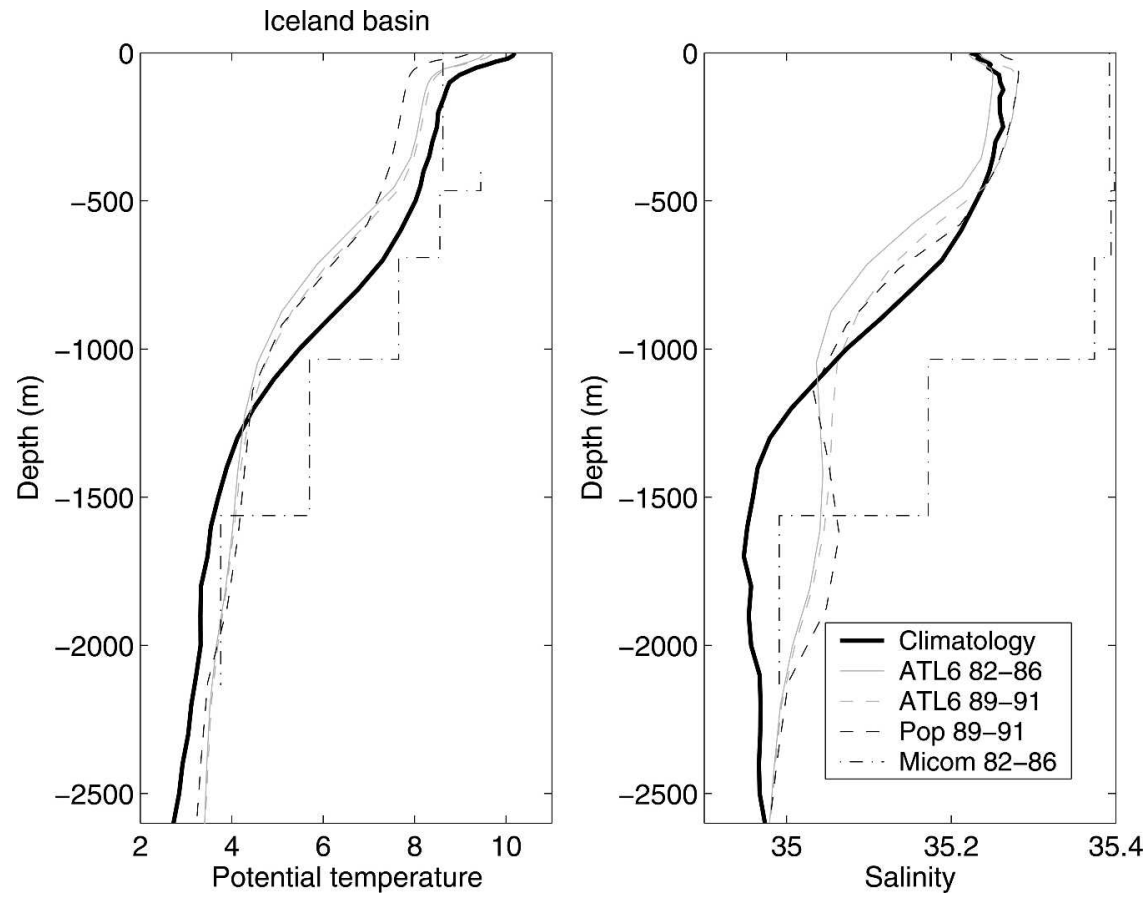

FIG. 11. As in Fig. 9 but over the Iceland Basin.

POPNA10 it is reasonable in the top $1000 \mathrm{~m}$. Below that level, a salinity minimum in the climatology shows the inflow of Labrador Sea Water; this inflow may be absent in the models (or the salinity of inflowing waters has increased).

The evolution of salinity in the three boxes for the ATL6 experiment (Fig. 12) shows a progressive salinization, with a trend that is still present after 28 years of experiment. The changes in salinity are stronger at the surface despite the relaxation to climatological salinity there. Exchanges with the atmosphere act to freshen the ocean; this also true in POPNA10 and FLAME. This points to erroneous salt transports, rather than surface fluxes, as the most important source for salinization.

\section{b. Mass transports}

Low-salinity water masses in the subpolar gyre originate in part from exchanges with the Nordic seas. To quantify those exchanges, mass transports have been calculated across Denmark Strait, the Iceland-Scotland Ridge, and a section from Greenland to Spain close to the WOCE section A25 (Alvarez et al. 2002). The sections, indicated in Fig. 13, form a closed domain. The transport through the English Channel is small (0.1 Sv) and is not indicated in the figure. The mass transports are calculated in two isopycnal layers, above and below $\sigma_{0}=27.8$, for comparison with the study of Dickson and Brown (1994, hereinafter DB94). This isopycnal lies between Nordic seas overflow waters and Labrador Sea Water. In ATL6, FLAME, and POPNA10, the transports are estimated using the model's density and velocity fields, time-averaged point-by-point at fixed depth. To get the true fluxes, the instantaneous mass fluxes above and below $\sigma_{0}=27.8$ should be computed for each snapshot and then averaged. This is automatically done in MICOM since the fields are timeaveraged point-by-point at fixed density. A calculation has been performed using ATL6 instantaneous fields in order to evaluate the importance of the eddy-induced (or "bolus") velocities resulting from the correlation of
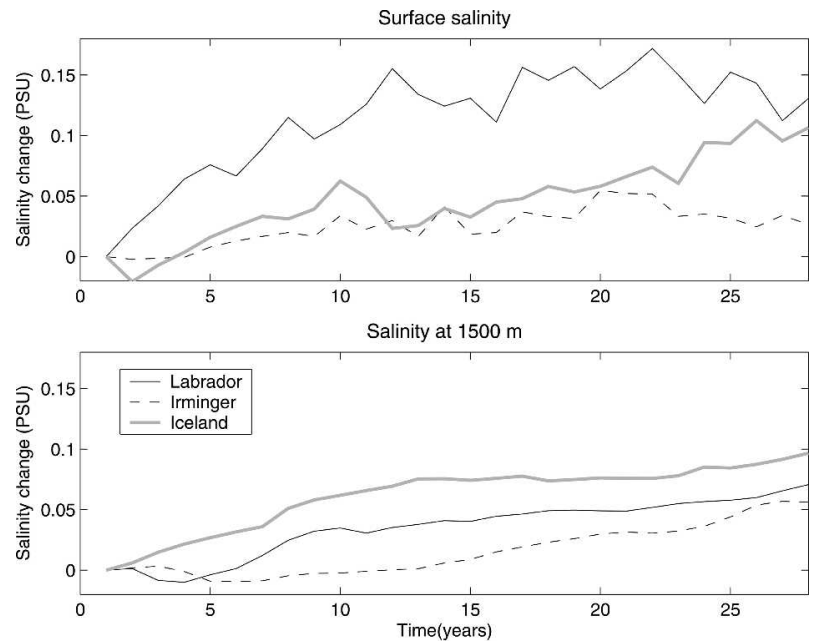

FIG. 12. Evolution of the annual average of salinity in the boxes of Fig. 8 in the ATL6 model. Changes relative to the first year of the model spinup are shown. 
(a)

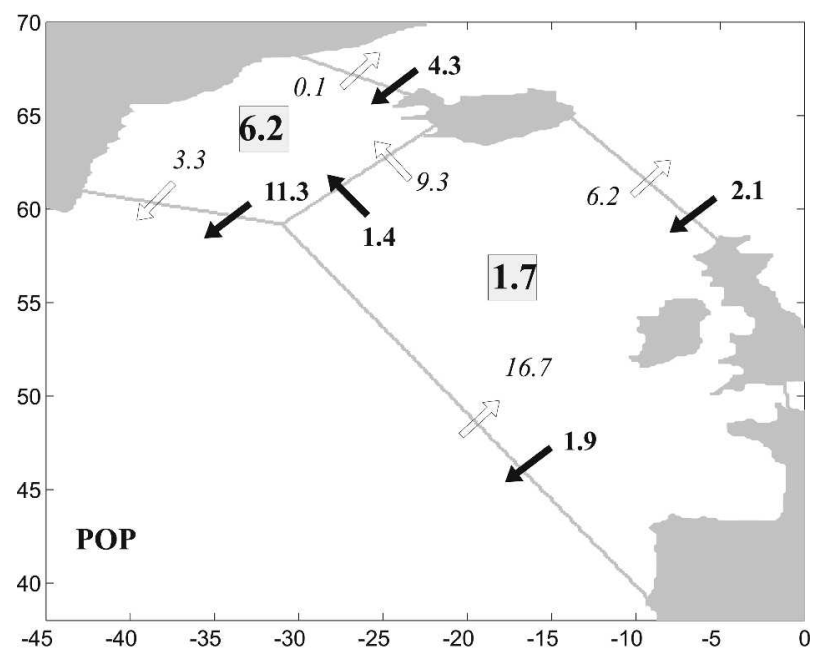

(b)

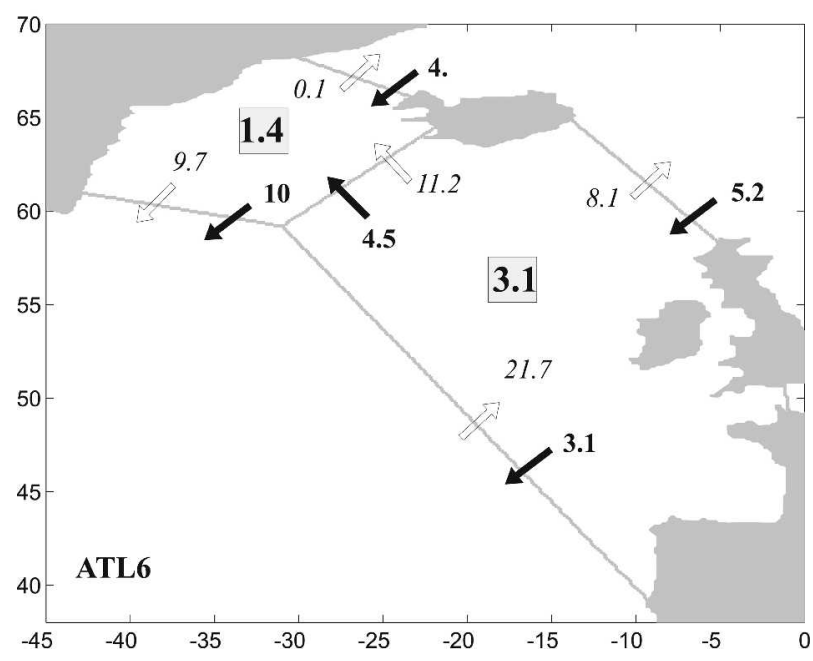

(c)

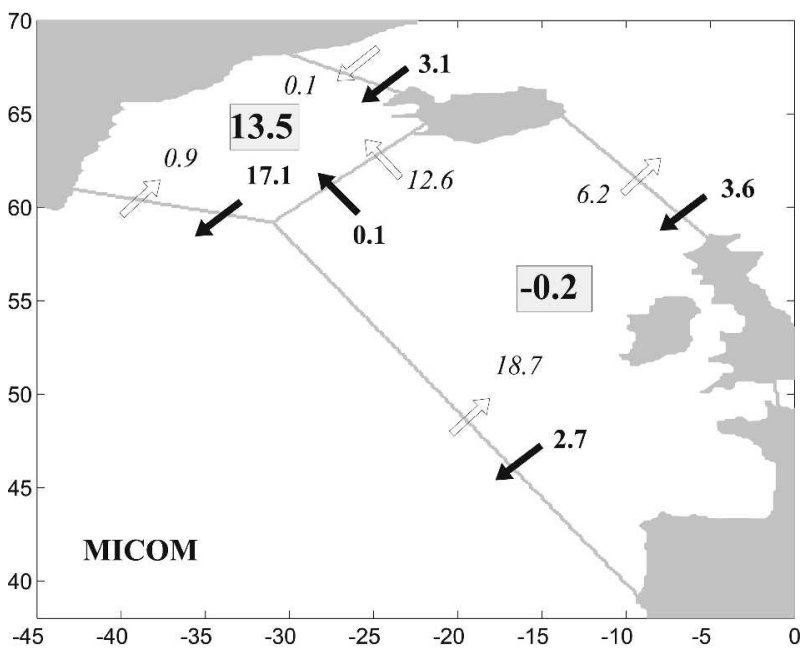

(d)

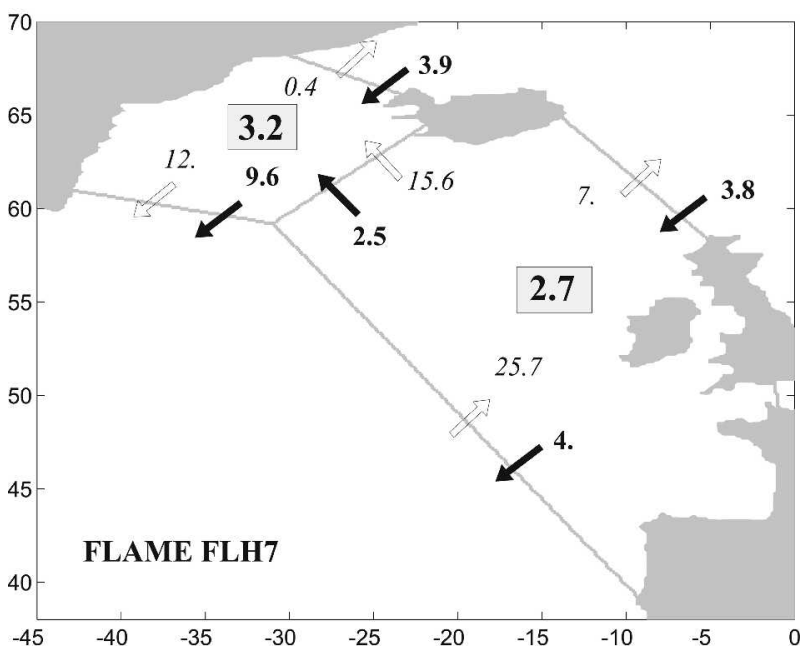

FIG. 13. Mass transports above (white arrows) and below (black arrows) isopycnal $\sigma_{0}=27.8$. Units are Sverdrups. The number in the boxes represents the conversion of light into dense water (positive downward). For ATL6 the balance is drawn for years $1989-91$.

isopycnal layer thickness and velocity. Although the eddy activity is large (especially along the North Atlantic Current, also in Denmark Strait) eddy-induced transports represent only a few percent of the total transports along the sections of Fig. 13. In the following, we assume the transports presented in Fig. 13 are comparable between models.

Let us consider first the deep water (black arrows). The inflow of deep water at Denmark Strait is consistent between models and also in rough agreement with DB94 estimates (2.9 Sv, their Fig. 13). It is highest in POPNA10 (4.3 Sv), intermediate in FLAME (3.9 Sv) and ATL6 (4 Sv for years 1989-91 and 3.7 Sv for years 1982-86) and lowest in MICOM (3.15 Sv). Regarding the Iceland-Scotland overflow, there is more variability between models. ATL6 has a large transport of $5.2 \mathrm{~Sv}$ (identical for the two time periods), FLAME has $3.8 \mathrm{~Sv}$,
MICOM has 3.6 Sv, and POP has 2.1 Sv, close to the estimate of DB94 $(2.7 \mathrm{~Sv})$. The larger value in ATL6 may result from the topography (special care has been taken to open the Faroe Bank channel in ATL6, perhaps opening it too much) and/or free-slip boundary conditions.

The net transport of deep water out of the Irminger Sea is 9.6 Sv in FLAME, 9.3 and $10 \mathrm{~Sv}$ in ATL6 (for years 1982-86 and years 1989-91, respectively), and $11.3 \mathrm{~Sv}$ in POPNA10, in good agreement with DB94. MICOM has a much larger transport of dense water $(17.1 \mathrm{~Sv})$, out of which 7.4 Sv are in the mixed layer. Much of this dense mixed layer water is probably formed in the Irminger Sea by air-sea fluxes, a process that may be different in MICOM than in other models because there is no vertical resolution in the surface mixed layer. 
There is a continuity of the deep-water flow along the East Greenland coast from Denmark Strait to Cape Farewell. Observations show that this flow is concentrated in a deep western boundary current with a welldefined core deeper than $2000 \mathrm{~m}$ (DB94). Such a deep core of maximum velocity is found in none of the models. This is expected in $z$-coordinate models, where entrainment is enhanced by the straircase representation of the topography. Here we find that entrainment may be too strong in MICOM as well. The entrainment parameterization has been calibrated for the Mediterranean outflow plume by Papadakis et al. (2003), and they have found the calibration to be quite sensitive to numerical parameters. It may prove necessary to tune the parameterization to each overflow separately. The transport of deep water around Cape Farewell is larger than the integrated value shown in Fig. 13 because there is a large recirculation into and out of the Irminger Sea. The pattern of recirculation in the dense water layer (not shown) is similar to the depthintegrated transport pictured in Fig. 5. POP agrees with DB94 picture, with recirculation coming in mainly from the Labrador Sea around $37^{\circ} \mathrm{W}$, and an Irminger Current transporting a few Sverdrups of deep water. ATL6 and MICOM depart from the DB94 scheme with a large transport of the Irminger Current.

Dense water $\left(\sigma_{0}>27.8\right)$ is not observed over the Reykjanes Ridge in the climatologies. A flow of deep water over the ridge exists in ATL6 (4.5 Sv) and FLAME FLH7 (2.5 Sv) because densities have become much larger than their climatological values in the area. The transport of deep water over the Reyjanes Ridge is smaller in the other two models.

Considering now the surface waters, all three models give a similar picture for integrated transports (although recirculations are different). The outflow of warm water into the Nordic seas over the IcelandScotland Ridge ranges from 6.2 (POP) to $8.1 \mathrm{~Sv}$ (ATL6), compatible with the value of $7 \mathrm{~Sv}$ found recently in the context of the Variability of Exchanges in the Northern Seas (VEINS) project.

Perhaps the most surprising feature is the large transport across the Reyjkanes Ridge section, from $9.3 \mathrm{~Sv}$ in POPNA10 to 15.6 in FLAME. The visual impression from the vector plots (Figs. 2 and 3 ) is that of a flow around Reykjanes Ridge (following $f / H$ contours) rather than across it. Nevertheless, the exact calculation along the sections of Fig. 13 leads to a significant transport across the ridge. Most of the warm Atlantic waters flowing to the northeastern Atlantic (from 16.7 Sv in POP to $25.7 \mathrm{~Sv}$ in FLAME) recirculate over the Reykjanes Ridge with at most a few Sverdrups being converted into water denser than $\sigma_{0}=27.8$. A cross-ridge transport of that magnitude is consistent with the circulation scheme of Schmitz and McCartney (1993, their Fig. 8) and is implied by most other quantitative studies of the circulation. There is an agreement on an inflow of upper layer water of order 15-20 Sv from the North
Atlantic Current east of the Reykjanes Ridge, and most authors also agree on an outflow of order $7 \mathrm{~Sv}$ over the Iceland-Scotland Ridge. The existence of a flow of warm water crossing the Reykjanes Ridge is the simplest way to account for the difference. As an example, one may consider the circulation estimate of Bacon (1997, his Fig. 18a). With a flow of 7 Sv into the Norwegian Sea, it would be compatible with a flow of $12 \mathrm{~Sv}$ over the Reykjanes Ridge.

The net mass balance is indicated in Fig. 13 for the western and eastern parts of the domain separately. The numbers represent a conversion of warm water into cold water: the volume drifts over the timeaveraging period, of order $0.5 \mathrm{~Sv}$, are taken into account and added to the flux convergence (excepted for FLAME, because the time period for the diagnostics is only one year). The numbers (especially in the Irminger Basin) vary widely from one model to the next and should probably be considered with caution since eddy effects have not been taken into account.

\section{c. Salt balance}

Salt fluxes have been calculated. The differences between models reflect the differences in mass transports. The salinization in the east and west subdomains occurs at a rate of $0.5 \mathrm{kton} \mathrm{s}^{-1}$ or less, at least one order of magnitude smaller than the convergence of horizontal fluxes (which is balanced, at first order, by the surface flux of freshwater). Because the salt imbalance is a small residual, it is difficult to identify one particular feature of the circulation as its cause. Two important sources of freshwater for the subpolar gyre are the lowsalinity waters resulting from ice melt lying on the continental shelves of Baffin Bay, the western Labrador Sea, and East Greenland. Regarding the Labrador Sea, a layer of low-salinity water is observed near the surface in the annual mean, but it is not well represented by the models. Low salinities are maintained in the top model layer in ATL6 and POP by relaxation to climatology, but they do not penetrate beyond 20-m depth. In MICOM, vertical resolution is too low to represent the thin cap of freshwater. Explicit representation of freshwater flux and river runoff allows the ATL6 model to maintain a salinity lower than climatology in the Labrador Current on the shelf, but those freshwater masses do not spread into the interior. In the real ocean, this spreading process is assumed to result from eddy activity and recirculation. It is not well represented in the models considered here and constitutes a major source of salinization.

Another source of freshwater is clearly underestimated: it is the East Greenland coastal current (EGCC) (Bacon et al. 2002), a swift and thin current flowing above the East Greenland continental shelf. This current is absent in ATL6 and MICOM. In ATL6, the current cannot exist because of spurious shallow areas in the shelf topography (an early version of the Smith and Sandwell 1997 bathymetry was used). In MICOM, 
the current may be weak because of the lack of vertical resolution (only the mixed layer is present on the shelf). The EGCC exists in POP, with a mass transport of 2.6 $\mathrm{Sv}$ at $60^{\circ} \mathrm{N}$, larger than the value of $0.8 \mathrm{~Sv}$ calculated by Bacon et al. (2002). Its existence may seem surprising because Bacon et al. argue that the real EGCC is forced by density contrasts resulting from ice melt. The POP model EGCC may be partly forced by relaxation to low density water existing in the climatology, but we believe this current is also partly forced by the wind. This is suggested by a recent study of Biastoch et al. (2003). Despite its strong transport, the POP model EGCC brings too little freshwater south because the salinity on the East Greenland shelf is high (34.3 psu, while Bacon et al. find values as low as $30 \mathrm{psu}$ ). This results in a salinity flux (referenced to $34.956 \mathrm{psu}$ ) of $0.44 \mathrm{~Sv}$ psu, $1 / 4$ of that estimated by Bacon et al.

Excessive salinization could also result from the large transport of salty water above or around Reykjanes Ridge. Certainly, when looking at the ATL6 model spinup, one sees at all depths a tongue of salty water coming from the eastern part of the basin being advected all around the subpolar gyre as far as the Labrador Current. Such a tongue is still apparent in the timemean field (see, e.g., Fig. 8 for the POP model). The comparison of velocity fields in section 3 suggested that the flow along the eastern flank of the Reykjanes Ridge may be wrong in the models: either overestimated (as suggested by the surface drifters) and/or also following too closely $\mathrm{f} / \mathrm{H}$ contours as suggested by the float data. If there is a recirculation of the current at the tip of Reykjanes Ridge, as hinted by the float data, this would help prevent salty waters from leaking into the Irminger basin.

\section{Conclusions}

This study is the first quantitative comparison between new velocity datasets and high-resolution models in the North Atlantic subpolar gyre. The improved resolution of both datasets and models allows us to discuss current branches and recirculations in more detail than before. However, most of the transport of the subpolar gyre occurs in boundary currents flowing along topographic slopes, and the density of float data in those boundary currents is not good enough for a quantitative comparison with Eulerian model results. Such a comparison may be possible in a Lagrangian framework by simulating float trajectories in the models; however even this could fail if real floats have a systematic tendency to leave (or not to enter) the boundary currents. All high-resolution models have a vigorous circulation around the subpolar gyre, which we believe is quite realistic; Eden and Böning (2002) have also come to that conclusion examining the results of the FLAME model in the Labrador Sea. This strong circulation, of order 40-50 Sv, contrasts with the results of the low-resolution models currently used in climate studies.

The high-resolution models that we have analyzed have not been run for the purpose of intercomparison, and it would have been too costly to perform dedicated experiments. It is a weakness, in the sense that we must take into account different forcing fields and integration strategies. Our conclusions about dynamical mechanisms must therefore remain tentative.

We think that the models presented here provide further evidence of a link between deep convection and barotropic circulation, demonstrated by Eden and Willebrand (2001) in the context of the interannual variability of a single model. In the conclusions of the DYNAMO intercomparison project, Willebrand et al. (2001) emphasize that deep convection has little influence on the meridional overturning (a conclusion previously put forward by Böning et al. 1996). The picture emerging is that of a meridional overturning primarily influenced by deep overflows, while the horizontal circulation of the gyre is influenced by both deep overflows and deep convection.

None of the models considered here is able to preserve observed watermass characteristics. This deficiency, and more specifically the salinization of the Labrador Sea Water, has often been attributed to problems with surface forcing or excessive mixing of the overflows. We believe that it is related to erroneous horizontal transports of salt in the present models. Our conclusion is markedly different from the one of Roberts et al. (1996) who compared low-resolution $\left(1^{\circ}\right)$ models. Those authors found that the reason for salinization in their models was the large freshwater fluxes near the North Atlantic Current (NAC) because the NAC path was too far south when compared with climatology (the surface freshwater flux being due to restoring to climatology). This process is likely to play a minor part here because the NAC path is much better represented than in the Roberts models (at least in POP, FLAME, and MICOM). Also, we have examined the evolution of salinity during the spinup in ATL6. Very large salinity anomalies appear in the first year in the East Greenland Current, in the Labrador Sea, and in the boundary current at depth, but the anomalies in the NAC are less intense and build up much more slowly.

Our study suggests that improvement of models in the subpolar gyre will be quite difficult. One missing source of salt (the East Greenland coastal current) may require an explicit sea ice model. Regarding the missing eddy salt fluxes in the Labrador Sea, higher horizontal resolution should help (Eden and Böning 2002; Chanut 2003) but when this is not possible, suitable parameterizations must be developed. The circulation around and above the Reykjanes Ridge should receive special attention. Models show that strong transports around the ridge (compatible with float data) do not exclude the existence of a large transport above the ridge (compat- 
ible with inverse estimates of the circulation). However, more data are needed to understand the relationship between the circulation and the salinity distribution. Eddies certainly play a part in the Irminger Sea, and a separation of the boundary current may occur at the tip of Reykjanes Ridge.

Acknowledgments. Authors A. M. Treguier, S. Theetten, and T. Penduff are supported by the Centre National de la Recherche scientifique (CNRS), E. P. Chassignet acknowledges support from the National Science Foundation Grant OCE-00-00042, and L. Talley was supported by National Science foundation grant OCE-9529584. Computing resources for the CLIPPER project were provided by the CNRS computing center IDRIS at Orsay, France. This work was initiated during a visit of $\mathrm{S}$. Theetten to the Scripps Institution of Oceanography.

\section{REFERENCES}

Alvarez, M., H. L. Bryden, F. F. Perez, A. F. Rios, and G. Roson, 2002: Physical and biogeochemical fluxes and net budgets in the subpolar and temperate North Atlantic. J. Mar. Res., 60, 191-226.

Bacon, S., 1997: Circulation and fluxes in the North Atlantic between Greenland and Ireland. J. Phys. Oceanogr., 27, 14201435.

—, G. Reverdin, I. G. Rigor, and H. M. Snaith, 2002: A freshwater jet on the east Greenland shelf. J. Geophys. Res., 107, 3068, doi:10.1029/2001JC000935.

Barnier, B., L. Siefridt, and P. Marchesiello, 1995: Thermal forcing for a global ocean circulation model using a three-year climatology of ECMWF analyses. J. Mar. Syst., 6, 363-380.

Beckmann, A., and R. Döscher, 1997: A method for improved representation of dense water spreading over topography in geopotential-coordinate models. J. Phys. Oceanogr., 27, 581591.

Biastoch, A., R. H. Kase, and D. B. Stammer, 2003: The sensitivity of the Greenland-Scotland ridge overflow to forcing changes. J. Phys. Oceanogr., 33, 2307-2319.

Böning, C. W., F. O. Bryan, W. R. Holland, and R. Döscher, 1996: Deep-water formation and meridional overturning in a highresolution model of the North Atlantic. J. Phys. Oceanogr., 26, 1141-1164

Bower, A. S., and Coauthors, 2002: Directly measured mid-depth circulation in the northeastern North Atlantic Ocean. Nature, 419, 603-607.

Bryan, F. O., C. W. Böning, and W. R. Holland, 1995: On the midlatitude circulation in a high-resolution model of the North Atlantic. J. Phys. Oceanogr., 25, 289-305.

Chanut, J., 2003: Paramétrisation de la restratification après convection profonde en mer du Labrador. Ph.D. thesis, Université Joseph Fourier, 160 pp.

Chassignet, E. P., and Z. D. Garraffo, 2001: Viscosity parameterization and the Gulf Stream separation. From Stirring to Mixing in a Stratified Ocean: Proc. 'Aha Huliko'a Hawaiian Winter Workshop, Honolulu, HI, University of Hawaii at Manoa, 37-41.

Clarke, R. A., 1984: Transport through the Cape FarewellFlemish Cap section. Rapp. P. V. Reun. Cons. Int. Explor. Mer., 185, 120-130.

Dengg, J., C. Böning, U. Ernst, R. Redler, and A. Beckmann, 1999: Effects of improved model representation of overflow water on the subpolar North Atlantic. International WOCE Newsletter, No. 37, WOCE International Project Office, Southampton, United Kingdom, 10-15.
Dickson, R. R., and J. Brown, 1994: The production of North Atlantic Deep Water: Sources, rates and pathways. J. Geophys. Res., 99, 12 319-12 341.

Eden, C., and J. Willebrand, 2001: Mechanisms of interannual to decadal variability of the North Atlantic circulation. J. Climate, 14, 2266-2280.

— Labrador Sea. J. Phys. Oceanogr., 32, 3346-3363.

Flatau, M. K., L. D. Talley, and P. P. Niiler, 2003: The North Atlantic Oscillation, surface current velocities, and SST changes in the subpolar North Atlantic. J. Climate, 16, 23552369.

Häkkinen, S., and P. B. Rhines, 2004: Decline of the subpolar North Atlantic circulation during the 1990s. Science, 204, $555-559$.

Käse, R. H., A. Biastoch, and D. B. Stammer, 2001: On the middepth circulation in the Labrador and Irminger Seas. Geophys. Res. Lett., 28, 3433-3436.

Lavender, K. L., R. E. Davis, and W. B. Owens, 2000: Mid-depth circulation observed in the interior Labrador and Irminger Seas by direct velocity measurements. Nature, 407, 66-68.

,-- , and — 2002: Observations of open-ocean deep convection in the Labrador Sea from subsurface floats. J. Phys. Oceanogr., 32, 511-526.

Levitus, S., 1982: Climatological Atlas of the World Ocean. NOAA Prof. Paper 13, 173 pp. and 17 microfiche.

Madec, G., P. Delecluse, M. Imbard, and C. Levy, 1998: OPA 8.1 general circulation model reference manual. Notes de l'IPSL, Université P. et M. Curie, No. 11, 91 pp.

Myers, P. G., 2002: SPOM: A regional model of the subpolar North Atlantic. Atmos.-Ocean, 40, 445-463.

— and D. Deacu, 2004: Labrador Sea freshwater content in a model with partial cell topographic representation. Ocean Modell., 6, 359-377.

Pacanowski, R. C., 1996: MOM 2 documentation: User's guide and reference manual. GFDL Ocean Tech. Rep. 3.1, 329 pp. [Available from Geophysical Fluid Dynamics Laboratory, NOAA, Princeton NJ 08540].

_, and S. G. H. Philander, 1981: Parameterization of vertical mixing in numerical models of tropical oceans. J. Phys. Oceanogr., 11, 1443-1451.

Paiva, A. M., and E. P. Chassignet, 2001: The impact of surface flux parameterizations on the modeling of the North Atlantic Ocean. J. Phys. Oceanogr., 31, 1860-1879.

— J. T. Hargrove, E. P. Chassignet, and R. Bleck, 1999: Turbulent behavior of a fine mesh $\left(1 / 12^{\circ}\right)$ numerical simulation of the North Atlantic. J. Mar. Syst., 21, 307-320.

Papadakis, M. P., E. P. Chassignet, and R. W. Hallberg, 2003: Numerical simulations of the Mediterranean Sea outflow: Impact of the entrainment parameterization in an isopycnic coordinate ocean model. Ocean Modell., 5, 325-356.

Pickart, R. S., D. J. Torres, and R. A. Clarke, 2002: Hydrography of the Labrador Sea during active convection. J. Phys. Oceanogr., 32, 428-457.

Redler, R., and C. W. Böning, 1997: Effect of the overflows on the circulation in the subpolar North Atlantic: A regional model study. J. Geophys. Res., 102, 18 529-18 552.

Reverdin, G., P. P. Niiler, and H. Valdimarsson, 2003: North Atlantic Ocean surface currents. J. Geophys. Res., 108, 3002, doi:10.1029/2001JC001020.

Reynaud, T., A. Waever, and R. Greatbach, 1995: Summer mean circulation of the northwestern Atlantic Ocean. J. Geophys. Res., 100, 779-816.

—, P. Legrand, H. Mercier, and B. Barnier, 1998: A new analysis of hydrographic data in the Atlantic and its application to an inverse modeling study. International WOCE Newsletter, No. 32, WOCE International Project Office, Southampton, United Kingdom, 29-31.

Roberts, M. J., R. Marsh, A. L. New, and R. A. Wood, 1996: An 
intercomparison of a Bryan-Cox-type ocean model and an isopycnic ocean model. Part I: The subpolar gyre and highlatitude processes. J. Phys. Oceanogr., 26, 1495-1527.

Schmitz, W. J., and M. S. McCartney, 1993: On the North Atlantic circulation. Rev. Geophys., 31, 29-49.

Smith, R. D., J. K. Dukowicz, and R. C. Malone, 1992: Parallel ocean general circulation modelling. Physica D, 60, 38-61.

— M. E. Maltrud, F. O. Bryan, and M. W. Hecht, 2000: Numerical simulation of the North Atlantic Ocean at $1 / 10^{\circ} . J$. Phys. Oceanogr., 30, 1532-1561.

Smith, W. H. F., and D. T. Sandwell, 1997: Global seafloor topography from satellite altimetry and ship depth soundings. Science, 277, 1956-1962.
Spall, M. A., and R. S. Pickart, 2003: Wind-driven recirculations and exchange in the Labrador and Irminger Seas. J. Phys. Oceanogr., 33, 1829-1845.

Treguier, A. M., and Coauthors, 2001: An eddy permitting model of the Atlantic circulation: Evaluating open boundary conditions. J. Geophys. Res., 106, 22 115-22 129.

- N. G. Hogg, M. Maltrud, K. Speer, and V. Thierry, 2003: The origin of deep zonal flows in the Brazil Basin. J. Phys. Oceanogr., 33, 580-599.

Willebrand, J., and Coauthors, 2001: Circulation characteristics in three eddy-permitting models of the North Atlantic. Progress in Oceanography, Vol. 48, Pergamon, 123-161. 